\title{
The evidence of impact and ethical considerations of Multimodal Learning Analytics: A Systematic Literature Review
}

\author{
Haifa Alwahaby [0000-1111-2222-3333] Mutlu Cukurova ${ }^{1[111-2222-3333-4444]}$ Zacharoula \\ Papamitsiou 2[0000-1111-2222-3333] and Michail Giannakos 2[1111-2222-3333-4444] \\ ${ }^{1}$ UCL knowledge Lab, University College London, UK \\ ${ }^{2}$ Norwegian University of Science and Technology, Trondheim, Norway
}

\begin{abstract}
There is a growing interest in the research and use of multimodal data in learning analytics. This paper presents a systematic literature review of multimodal learning analytics (MMLA) research to assess i) the available evidence of impact on learning outcomes in real-world contexts and ii) explore the extent to which ethical considerations are addressed. A few recent literature reviews argue for the promising value of multimodal data in learning analytics research. However, our understanding of the challenges associated with MMLA research from real-world teaching and learning environments is limited. To address this gap, this paper provides an overview of the evidence of impact and ethical considerations stemming from an analysis of the relevant MMLA research published in the last decade. The search of the literature resulted in 663 papers, of which 100 were included in the final synthesis. The results show that the evidence of real-world impact on learning outcomes is weak, and ethical aspects of MMLA work are rarely addressed. We discuss our results through the lenses of two theoretical frameworks for evidence of impact types and ethical dimensions of MMLA. We conclude that for MMLA to stay relevant and become part of mainstream education, future research should directly address the gaps identified in this review.
\end{abstract}

Keywords: Multimodal Learning Analytics, Ethics, Impact Evaluations.

\section{Introduction}

Multimodal data (MMD) streams and complex artificial intelligence (AI) modelling techniques are increasingly being deployed in learning analytics research to help us better understand, model and support teaching and learning processes (Sharma \& Giannakos, 2020). This area of research has grown during the last years and is generally referred to as Multimodal Learning Analytics (MMLA) (Blikstein \& Worsley, 2016). Recent individual and review studies show that MMD and AI approaches can significantly improve the performance of learning and teaching models (Cukurova et al., 2019; Giannakos et al., 2019). However, the increased use of AI techniques and fine 
granular MMD adds new challenges and worries about the role of such interventions in educational contexts (Cukurova, Giannakos, et al., 2020). There are various "horror stories" of bias and discrimination, of the denial of individual autonomy and rights, non-transparent and unjustifiable outcomes, invasion of learner and teacher privacy, unfair, unequal, unreliable, and unsafe outcomes for humans involved in the use of such interventions in education (Andrejevic \& Selwyn, 2020; Knox et al., 2020; Selwyn, 2020).

MMD and AI techniques have been used since the 1950s (i.e McCarthy, 1959), yet it is only in recent years they are popularly used in teaching and learning research, but still limited in practice. To be able to reap the benefits of MMD and AI in teaching and learning research and practice, there is an urgent need to (a) provide the evidence of impact for MMLA systems to achieve educational outcomes, and (b) to create plans and tools to address the ethical difficulties outlined above.

The ethical concerns are deeply and inherently intertwined with the evidence of impact evaluations in MMLA, and in Educational Technology research in general. This is mainly due to two reasons. First, the adoption of MMLA tools and research in the real world are dependent upon the valuable evidence (documented benefits) and the mitigation of potential risks (e.g., ethical risks). Second, to a certain extent, the deployment of MMLA tools in educational settings that are not impactful (or at least promising potential evidence for impact) and does not meet the minimal risk standards ${ }^{1}$ may be considered an unethical deed. Therefore, here, we present a systematic literature review (SLR), following the guidelines of Kitchenham and Charters (2007) to examine the empirical evidence on the impact of MMLA and how contemporary MMLA research tackles its inherent ethical challenges. More specifically, we address the following two research questions.

$\boldsymbol{R Q 1}$ : What is the existing evidence on the use of MMLA systems to support educational outcomes in real-world settings?

$\boldsymbol{R Q 2 :}$ To what extent ethical considerations are highlighted and addressed in MMLA research?

This SLR provides information about the current practices, limitations and considerations of MMLA research across a wide range of learning and teaching settings, contexts and empirical methods, with a focus on the impact and ethical aspects of MMLA. The motivation behind this work is to identify the main barriers to the development of MMLA research and encourage future research directions that help us to overcome those barriers. Although the MMLA field is still relatively young, this review work is timely and important for the field to grow in a direction that would lead it to become a part of mainstream education research and practice. In the following sections, we first synopsize the background on MMLA to highlight what it entails and what is currently missing. Next, we explain the methodology employed for conducting the SRL and present the results of this process. We conclude the paper with a comprehensive discussion of the findings as well as their implications for the field, and the limitations of the selected methodological decisions.

\footnotetext{
${ }^{1}$ Paraphrasing the definition from the Electronic Code of Federal Regulations (www.ecfr.gov) a risk is minimal where the probability and magnitude of harm or discomfort anticipated are not greater, in and of themselves, than those ordinarily encountered (within the same context/task).
} 


\section{Background and Related Work}

MMD can provide valuable information that can contribute significantly to gaining indepth insights into the learning processes and strategies (Giannakos et al., 2019; Worsley \& Blikstein, 2015). Learning Analytics (LA) researchers have long been depending on conveniently collected unimodal data (usually coming from the log files of a digital learning environment) as their main quantitative source of information (e.g., see a recent literature review, Mangaroska \& Giannakos, 2019). However, nowadays a variety of new sensing technologies offer a wide range of data sources such as eye gaze, heartbeats and human body tracking which can offer more granular details of learner and teacher interactions and information processing. Recently, an increasing number of researchers have started investigating the role of MMLA to inform the learning and teaching process. There have been multiple literature reviews and surveys published within the last five years (Crescenzi-Lanna, 2020; Di Mitri et al., 2018; Sharma \& Giannakos, 2020), and a few special issues in influential academic journals (Cukurova, Giannakos, et al., 2020; Drachsler \& Schneider, 2018), summarising the state-of-theart research in MMLA. More specifically, (Cukurova, Giannakos, et al., 2020) edited a special section with ten contributions shedding light on the promise and challenges of MMLA, with the main challenges categorised as ethical, practical and methodological issues. Another special issue edited by Drachsler and Schneider (2018), included seven articles focusing on the effects of MMD on the learning and teaching sciences. The editorial of this special issue highlighted that this line of research is opening a new way to analyse learning behaviour, feedback and open source tools, yet there was no particular discussion on the potential challenges brought by the use of MMLA systems in real-world educational settings.

Along the same lines, recent literature reviews of MMLA research acknowledge the lack of a critical positioning of researchers as a significant gap in the current literature. For instance, Blikstein and Worsley (2016) argued on the importance of MMLA to provide in-depth insights about pedagogies, such as problem-solving learning and students' interaction with others, aiming at assessing the feasibility of MMLA as an assessment tool in several learning contexts. The review synopsized the methods that have been used to capture and process student data and focused on different techniques (e.g., text analysis, speech analysis, handwriting analysis, gesture analysis, affective state analysis, gaze analysis), without though, focusing on the challenges of real-world implementations or ethical considerations. In another literature survey, Di Mitri et al. (2018) analyzed the empirical works on the use of MMD and the learning theories selected. Their work resulted in a taxonomy that maps the use of MMD to enhance feedback in a learning context, shows ways of combining ML with MMD, and develops common nomenclature for the research fields involved (i.e., ML, the learning sciences and MMD). However, again, there was no particular focus on the potential drawbacks of MMLA used in educational research and practice, or any of the underlying ethical considerations.

Recently, Chua et al. (2019) reviewed 66 cases of tools and technologies that have been developed to collect and analyze MMD. The authors focused on the methodological developments in the field and identified the data sources and modalities, outcomes, targets of assessments, deployment settings, units of analysis, and the maturity level of the developed technologies. The analysis revealed the lack of 
studies that utilize deep learning algorithms. The authors suggested that future research should focus on deployable and sustainable set-ups for data collection in physical spaces, teacher assessment, developing systems for feedback and visualization, promoting generalized models across different populations, and explore how sensing technologies and devices can be adopted to make learning more accessible to people with disabilities. From a different perspective, Sharma and Giannakos (2020) focused on what and how MMD have been used to inform learning and in what contexts. The summarized papers were framed within six thematic areas (behavioural trajectories, learning outcome, learning-task performance, teacher support, engagement and student feedback) and elaborated on the capabilities of MMD for learning. Sharma and Giannakos (2020) emphasized that future research should develop a framework to enable MMD capacities (i.e., what insights MMD can offer for learning) to be aligned and contextualized with the research goals and learning designs of the particular MMLA research/application.

Another recent review by Crescenzi-Lanna (2020) covered MMLA research involving children under six years old. The author analyzed the contributions using various scales such as performance analytics (students' understanding and engagement), the use of ML, MMD and qualitative data (annotations, interview, observation). Arguably, the most intriguing contribution of this review was that the author also commented on potential ethical issues (e.g., children being lied to in a "Wizard of Oz" experiment in which children have been told that a robot can understand and answerer their questions while the answers have been directed from technicians in the same room; longer and obtrusive exposure to experiments; effect on data quality of the interaction with strangers who are researchers; anonymity). Besides, Beardsley et al. (2020) tackled the consent form particularities of MMLA research and introduced an informed consent comprehension test for MMLA studies. The authors assessed its effect based on learners' comprehension and rates of enrolment in an MMLA study. The focus of the paper was on consent forms, yet the paper did not discuss any evidence of impact or other ethical considerations involved in MMLA research.

Previous reviews covered above provide valuable information about the promise of MMLA, yet do not specifically focus on their real-world impact and ethical implications of MMD collection and utilization in LA. The evidence of the impact of MMLA systems on educational outcomes as well as research that aims to address potential ethical issues emerging from the use of these systems in practice is essential for the field's success and proliferation. In advance, ethical considerations in educational research, just as in other social sciences research, are fundamental to the future of the premise. Yet, to the best of our knowledge, there is no review work particularly investigating the ethical considerations of the MMLA studies. Therefore, there is a need for a critical review that focuses both on the evidence of impact and the inherent ethical challenges of MMLA research. Here, we aim to bridge that gap. The results of this review will allow MMLA researchers and practitioners to reflect upon their practices and methodological decisions, as well as nurturing discussions about the future development of MMLA research. 


\subsection{Ethical considerations of Learning Analytics}

MMLA research and practice can lead to significant concerns amongst educational stakeholders particularly with regards to the transparency, accountability, privacy, fairness and bias of such systems in real-world practice. One recent example of contextualising key dimensions of ethical considerations of learning analytics is presented by Hakami and Hernandez-Leo (2020). The authors discuss the importance of transparency, accountability and fairness (FAT) of Learning Analytics as well as covering some aspects of wellbeing. The ethical issues that emerge in the context of MMLA are also tightly interconnected with the multifaceted aspects of FAT. Therefore, such contextualisation examples can initiate the discussion on the ethics of MMLA research and can provide a useful theoretical framework to structure the complexity of the discussion. It is likely that due to MMD's potentially more invasive, highly granular, and temporal nature compared to log data sources, they might bring in further ethical challenges compared to more traditional learning activity data. Here, we summarise some of the potential key dimensions that have been discussed in LA literature broadly and need attention and contributions from the MMLA research community.

Transparency: According to Hoel et al. (2017) and Pardo, \& Siemens (2014), privacy and policy issues have a huge influence on the design of LA systems, thus, there is a critical need for an in-depth systematic treatment of ethical and data protection issues. For instance, institutional transparency is one of the ethical challenges that educational institutions should handle carefully. As discussed by Drachsler and Greller (2016), the level of transparency in a data model is important in the adoption of educational technology, thus, clear information should be available about the data collection, storing, processing and sharing. To address this issue a nine-point checklist named DELICATE for a trusted LA implementation was provided to support handling the data transparency issue. Moreover, there is a major concern about transparency in tracking learners' data. According to Duval (2011), people should be aware of while they are being tracked. Clarifying the reason behind the data collection might also help to tackle the transparency issue in education (Drachsler \& Greller, 2016). Besides, participants should have the option to opt-out from the data collection process at any stage without affecting the collection process as a means of data collection transparency based on a review of eight policies for learning analytics by Verbert et al. (2020). However, transparency is needed in all stages of the MMLA pipeline including the modelling and visualisations, and it is not only limited to data collection and processing. For instance, transparent and open learner models (OLMs) have been the centre of LA and EDM communities which can significantly benefit MMLA research. As shown by Abdi et al. (2020), complementing educational recommender systems (ERSs) with open learner models (OLMs) can have a positive impact on user's perceptions and engagement based on the results generated from a randomized controlled experiment. Similarly, as exemplified in recent research (Cukurova, Zhou, et al., 2020) a transparent model that predicts learners' collaborative problem-solving competencies from video data can be preferred over high performing yet non-transparent models. In this work, the authors developed transparent decision trees instead of using non-transparent deep learning and neural network approaches since the transparent models allowed teachers 
and learners to examine analytics' predictions. It was argued that understanding factors influencing learning outcomes measured in analytics, and avoiding "black-box" approaches where possible, can lead to an increase in human agency and adoption (Cukurova, Zhou, et al., 2020). Similar arguments were also echoed by Shibani et al. (2019) who argued that allowing educators to have control over the educational systems can promote the transparency and trustworthiness of the system. At the stage of visualizing the MMLA models, engaging students in the design development of the LA system beyond the standard focus group is needed to ensure a fully transparent design of the LA system (de Quincey et al., 2019). LA tools can be regarded as transparent tools when the process behind the LA output is clear enough to the users allowing them to review and critique the output with confidence (Shum et al., 2016). However, such propositions should be empirically tested with users in real-world contexts.

Accountability: In addition to the transparency dimension, the accountability concept has been tackled by some LA researchers, yet has not received much attention from the MMLA community. A requirements list for LA systems was developed and derived from the GDPR legal requirements point of view by Hoel et al. (2017), which argued that educational institutions should provide evidence on their system capability to protect users' data and prevent any breach of the system to provide institutional accountability. There is also a growing demand for algorithmic accountability in LA as stated by Knight et al. (2017) therefore complex analyses are required for analytics devices. For instance, according to Prestigiacomo et al. (2020), providing students with evidence generated from LA systems can promote students' accountability about their learning. In general, as argued by Gibson and Lang (2018) assessing the accountability and quality of LA is not easy; as a result, the Pragmatic Inquiry for Learning Analytics Research (PILAR) method was presented to address some of the quality and accountability questions related to LA research in general. To what extent such generic guidance can be contextualised in MMLA research and how they should be expanded to be more meaningful for MMLA are significant questions yet to be addressed.

Privacy: Recently, data privacy has become a pressing topic gaining significant interest by the LA researchers to increase the quality and trust in LA (Scheffel et al., 2014). Privacy challenges associated with LA include but are not limited to, data ownership, anonymization, collection, storing, processing and sharing of data. However, such discussions are missing from many institutional and educational policies (Prinsloo \& Slade, 2013; Slade \& Prinsloo, 2013). Drachsler and Greller (2016) presented the DELICATE checklist to check the privacy issues emerging with the use of LA technology.

Fairness and Bias: Different participants' varied backgrounds may affect their response to learning measurements which would lead to fairness issues in an educational system. Similarly, the generalizability of learning measurements with MMLA systems for a certain group might not apply to other groups (Milligan, 2018). As argued by Doroudi and Brunskill (2019) it is important to make sure that algorithms are equitable to different student populations when designing learning analytics systems. The authors suggest that knowledge tracing algorithms can offer more equitable solutions for certain student populations, yet, they could still be inequitable in comparison to other student populations (i.e. favouring fast learners over slow learners). In a similar vein, Verbert et al. (2020) state that there is a crucial need to address challenges related to ethical implications of predictive systems and bias in LA 
research in general. In that context, opening up the visualization of MMD used in predictive models can offer great opportunities to help end-users understand the decisions made by the predictive models of MMLA and reveal any underlying biases. Varied and large-scale data collection are important for model training of MMLA since the fairness of AI and ML-driven MMLA systems can be affected by many aspects such as race and gender. On the other hand, the collection and collation of data on these sensitive constructs to measure the algorithmic fairness of MMLA systems might be a challenging process by itself.

As summarized above, some key aspects that relate to the ethics of LA research have received attention from the LA research community. However, to what extent similar considerations are taken into account in MMLA research is yet unknown.

\section{Methodology}

For the objectives of this study, a systematic literature review (SLR) methodology was adopted. The methodological decisions of the SLR have been made with a focus on addressing the research questions and search for empirical evidence of real-world impact on learning outcomes and the respective ethical considerations of MMLA research. For the needs of the SLR, the present study was conducted in line with the PRISMA guidelines (Moher et al., 2009) to improve transparency, and according to a widely accepted procedure proposed by Kitchenham and Charters (2007). To ensure robustness, we enacted a protocol consisting of four explicit and discrete steps: a) define the keywords and digital libraries and intensively search the literature - i.e., data collection based on information sources and search strategies; b) review and assess the search results - i.e., screening and filtering out the unrelated papers according to explicit eligibility (inclusion/exclusion) criteria; c) analyze, code and synthesize the results; and d) report the findings in a comprehensive review. The time frame of the search focused on the literature published between 2010 and 2020 in which the emergence and adoption of Learning Analytics, as well as Multimodal Data in educational contexts, has grown.

The search process was conducted in two phases. In the first phase (Dec. 2019), four broadly acknowledged digital libraries (i.e., Scopus, Web of Science, IEEE and ACM Digital Library) were used as the information source. In addition, Google Scholar was included in the analysis, as the most widely used search engine that indexes almost every academic library. Google Scholar was searched by using the keywords "multimodal learning analytics". From the Google Scholar search the top 100 papers (from a total of 824) were considered, similar to previous systematic review work in the field (Matcha et al., 2019; Schwendimann et al., 2017). We aimed to focus on the use of digital sensing technology to understand/explain human learning mechanisms, thus, keywords were selected based on four main concepts: data modalities, learning, tools and physical spaces. The specific keywords included the following terms (both in singular and plural forms): multimodal data, multimodal learning analytics, sensing technologies, physical spaces, gesture recognition, tangible interactions, dashboards. The final keyword searches, for WOS, Scopus, ACM, IEEE respectively, are presented in Appendix A. The total amount of hits in the search was 663, and 442 entries after duplicate deletion. 
Two reviewers with learning analytics research backgrounds screened the titles and abstracts of the resulting 442 papers to determine their eligibility in terms of whether the study indeed involved a multimodal technology implemented in learning and educational contexts. This initial title and abstract screening of the 422 entries were completed by two researchers going through all entries separately and recommending for inclusion or exclusion. Reviewers stated applicable exclusion criteria. A total of 298 papers were recommended for inclusion after this initial screening. Further, among the 298 pre-selected entries, articles that did not satisfy the inclusion criteria were also excluded from the review with a full-text analysis. For the full-text analysis, randomly selected $10 \%$ of the remaining entries underwent a parallel selection process (30 papers in total) and inter-rater agreement was calculated (Cohen's Kappa=0.73). Disagreements between the two researchers were resolved through meetings and discussions about where the differences occur which led to further clarification of the screening criteria. The two researchers analysed papers according to specific eligibility criteria. Entries not related to MMLA, entries not related to learning and/or educational outcomes, entries with no full-text (extended abstracts/abstracts only, posters, demos, doctoral consortium papers), entries that are not empirical studies (e.g., editorials, discussion and opinion papers), and entries that were not published in English were all excluded from these pre-selected entries to enhance the rigour of the conclusions from the review. As a result, 71 papers were included in this review.

To include research papers published during the initial search, screening, and analysis period of the review study, a second search phase was conducted in Jan 2021. Following the same procedure of the first phase by the same two researchers, 29 additional papers were identified. Thus, in total 100 papers were included in this review. All entries identified in this study can be found in an online repository ${ }^{2}$ with access to their exclusion reasons. :

Next, papers were coded based on the data modalities they utilized, on the type of empirical evidence they provide (i.e., causal evidence, correlational evidence, descriptive evidence, anecdotal evidence, prototypes with no evidence, and machine learning), as well as whether the ethical aspects were taken into consideration or discussed. The labelling was agreed upon by two researchers. The taxonomy of modalities that has been used was deployed from a recent systematic review (Sharma $\&$ Giannakos, 2020). The categories of evidence types that have been used are based on previous research on the impact evaluations of educational technologies (e.g., (Cukurova \& Luckin, 2018)). We used a top-down approach based on our interest in different types of evidence and our interest in the existence of ethics discussions. Papers were coded first by one researcher and then another researcher went through the papers for cross-checking the results. The coders relied upon the explicit content directly appearing in the papers rather than interpreting what the authors have written.

Finally, the results were synthesized in a comprehensive report. Fig.1 below summarises the methodology used in this paper.

\footnotetext{
${ }^{2}$ https://data.mendeley.com/datasets/3d8gr3jjk2/draft?a=8b1ea571-f9dc-4a79-a7ec849431d587a6
} 


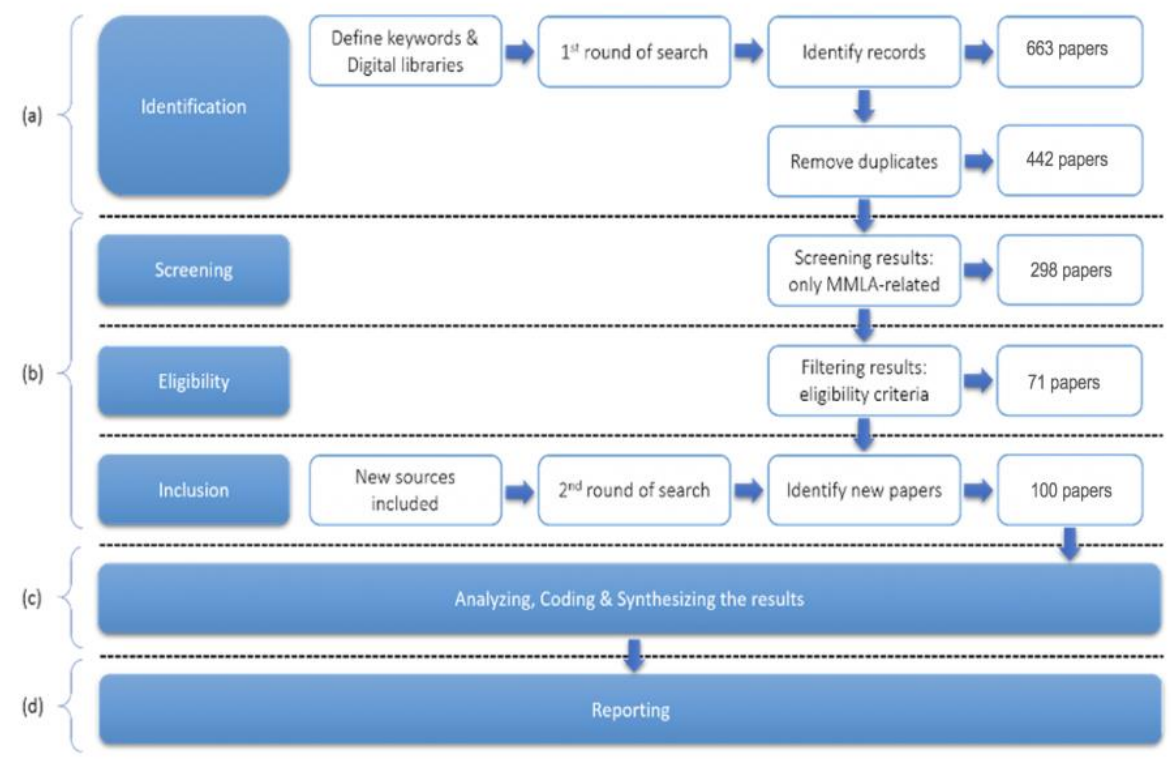

Fig. 1. The methodology used in this systematic literature review

\section{$4 \quad$ Results}

\subsection{Data Modalities Used in MMLA Research}

In this section, we briefly overview the data modalities and indicators that have been applied in contemporary MMLA research to provide a broad introduction to those readers who are not familiar with multimodal learning analytics. The goal of this review is not to describe the different modalities and their connection to teaching and learning, or to investigate the multimodal nature of MMLA, as those have already been welldocumented in previous reviews (e.g., Blikstein \& Worsley, 2016; Sharma \& Giannakos, 2020). However, this overview will set up a common understanding of the foundations of the field and will act as a lens to reveal the realistic distance between what MMLA research is utilizing and what real-world practice can afford. Consequently, it seeks to emphasize the need for ethical considerations and accelerate the developments in the field. As advanced sensing technologies are becoming more affordable for researchers to use, various data modalities and indicators are utilized to capture aspects and constructs of learning and teaching processes. Concrete examples found in our literature review are:

Audio and Video: The most ubiquitous MMLA data collection is the one connected with audio and video sensors. Such data collections are mainstream in learning sciences, as they support cornerstone methodologies stemming from both qualitative and quantitative research. In MMLA, those modalities are used to estimate the presenter's pose, gaze direction (Andrade, 2017; Ochoa \& Dominguez, 2020; Tan 
et al., 2020), dialogue's characteristics such as pitch (Olsen et al., 2020; Sharma, Leftheriotis, et al., 2020) and speech rate (Vrzakova et al., 2020). Another commonly used practice is employing the video modality to capture facial data (Ahn \& Harley, 2020; Lee-Cultura, Sharma, Papavlasopoulou, et al., 2020; Martin et al., 2019). Video techniques have also been used to capture students' motion activity by detecting body movements (Vrzakova et al., 2020; Vujovic et al., 2020) and the number of the facein-the-screen and distance metrics between bodies (Cukurova, Zhou, et al., 2020).

Eye-tracking: Another widely employed and "insightful" modality is eyetracking. Several MMLA studies employ eye-tracking to detect learners' concentration level, visual attention and habits (Emerson, Cloude, et al., 2020; Sharma, Leftheriotis, et al., 2020). The gaze is typically captured via ubiquitous solutions mounted to the screen (e.g., SMI, Tobii) (Mangaroska et al., 2020; Sharma, Papamitsiou, et al., 2020); eye-tracking glasses for tracking learners' gaze in off-screen activity (Papavlasopoulou et al., 2018), have also been utilized.

Skin sensing modalities: Another group of modalities, frequently used in MMLA, relates to data coming from learners' skin. Pijeira-Díaz et al. (2018) measured students' arousal and electrodermal activity (EDA) using wristbands. Dindar et al. (2020) recorded students' EDA during group work and combined the data with situated self-reports. Larmuseau et al. (2020)utilized several modalities such as galvanic skin response (GSR), skin temperature (ST), heart rate (HR) and heart rate variability (HRV) to infer students' cognitive load. More affordable devices, such as smart bracelets and sonic devices (utilizing sound waves), have also been employed to monitor students' activity during learning (Liu et al., 2018).

Location sensing modalities: Another category of modalities employed in MMLA research come from location sensing in the physical learning space (e.g., classroom). Martinez-Maldonado et al. (2018) utilized proximity data collected by the ultra-wideband (UWB) positioning tags to investigate students' positioning and movement during their lab instruction. Similarly, Martinez-Maldonado, Elliott, et al. (2020) used indoor localisation badges and Martinez-Maldonado, Echeverria, et al. (2020) tracked positioning data through wearable (Pozyx.io) tags to generate multimodal data insights in the context of nursing education. Martinez-Maldonado, Mangaroska, et al. (2020) captured teachers positioning data with the Pozyx.io ultrawideband (UWB) system and via UWB indoor positioning badge worn by the teachers to make visual representations for location trace to support teaching. Other work by Hsieh et al. (2010) tracked location and time using wireless detectors to support cooperative learning activities in classrooms. Wireless sensors were also used by Riquelme et al. (2020) where students' movements were tracked by beacons to track collaborative behaviour.

Multimodality: The aforementioned modalities and the respective insights allow researchers and practitioners to capture information that can reinforce their teaching (e.g., awareness, reflection) and enrich their learning design overall (Sharma $\&$ Giannakos, 2020). Yet, the power of MMLA mainly comes from the triangulation of insights coming from different modalities. For example, data modalities were collected including gaze, electrodermal activity, movement and position data to predict the quality of collaborative problem solving (Reilly \& Schneider, 2019; Schneider, 
2019). In another example by Boulton et al. (2018), multiple data modalities were also captured including, facial expression, the position of the learner, and their affective state. Overall, we see that the utilization of the various data modalities is the key feature in allowing us to holistically capture students' interactions and identify in-depth insights into the learning processes and strategies. It is important to note that investigating whether the multimodality was provided with a triangulation approach or a fusion of data approach was not within the scope of this review. Those readers who are interested in such distinctions are referred to a recent literature review (Mu et al., 2020) addressing this question. Table 1 in Appendix B summarises the modality used in the included papers and Fig.2 in Appendix C presents the distribution of papers belonging to each modality category.

\subsection{Existing evidence on the use of MMLA to support educational outcomes}

In this section, we address the first research question, which relates to the impact of technology on learning outcomes which is often at the forefront of demands from key educational stakeholders, including teachers, learners, parents, and policy-makers. This is not an unreasonable request; generating evidence on the impact of MMLA is necessary to justify our confidence in its potential to meet its expected educational value. Relying on empirical evidence (data received from the senses) and the respective epistemic stance (empiricism), we leverage the collected MMLA studies to address the research objective of this paper. In particular, this section addresses the first research question that focuses on the existing evidence on the use of MMLA to support educational outcomes. The papers are divided into six categories based on the evidence they provide: causal, correlational, descriptive, anecdotal, machine learning, and MMLA systems with no impact evaluations.

Causal Evidence: Causality can be achieved by ensuring that the only difference between the group that receives an educational technology intervention and the comparison group is the intervention itself. Many guidelines for evidence-based practice indicate that the best-quality evidence comes from randomized controlled trials (RCTs) (Connolly et al., 2018). For increasing the trust of educational stakeholders in the value of MMLA for teaching and learning practice, it is essential to generate reliable causal evidence. In our systematic search, ten studies argued to provide causal evidence on the impact of an MMLA system, although among these 10 only one study used a randomized controlled trial methodology (Ochoa, \& Dominguez (2020)). For instance, Ochoa \& Dominguez (2020) evaluated the impact of an MMLA system in facilitating the acquisition of oral presentation skills. The results show that oral presentation skills can indeed be improved with the feedback provided by the MMLA system. Yet, the long-term engagement with the tool was suggested, and the impact of the systems' feedback was still inferior to expert human's feedback. Oviatt et al. (2015) examined simultaneous speech in groups of students as they jointly solved math problems and peer tutored one another and the results showed that simultaneous speech was associated with domain expertise and highly productive phases during group problemsolving interactions. Junokas et al. (2018) presented an adaptable model for gesture 
recognition of student interaction to develop stronger connections between students' physical actions and digital representations within a multimodal space, their results showed that there were statistically significant differences between the one-shot model and the pre-trained model groups in all three stages. Papavlasopoulou et al. (2018) presented a study to utilize eye-tracking to understand children's activity while they learn how to code and to investigate any potential association between children's attitudes and their gaze. Their results showed a significant relationship between children's attitudes (what they think about coding) and their gaze patterns (how they behaved during coding). Ahn and Harley (2020) investigated emotions' influence on learning outcomes, revealing that learners with an angry emotion profile had the highest learning gains. Larmuseau et al. (2020) captured physiological data to measure cognitive load during online complex problem-solving. The results showed that heart rate and skin temperature were significantly related to self-reported cognitive load, whereas skin temperature to task performance improved speaking time distribution and enhanced teacher intervention performance. Cornide-Reyes et al. (2020) presented NAIRA, a real-time feedback visualization platform for students' verbal interactions to promote group work activities and showed that NAIRA helped teachers to monitor and facilitate the collaborative learning activity even remotely in virtual classrooms. Furthermore, the quantitative comparison of spoken interactions revealed differences in the distribution of speaking time between the monitored and unmonitored stages, with the NAIRA-supported stage showing a more homogeneous distribution of talking time. As part of a dual eye-tracking study, Sharma, Leftheriotis, et al. (2020) examined students' collaboration, engagement, and learning outcomes during a learning activity and found that collaborative pairs that share a similar gaze achieve better learning. Vujovic et al. (2020) studied the role of table shape on student behaviour in collaborative problem-solving tasks and found that round tables have a positive impact on students' level of participation. Lee-Cultura et al. (2020) found that the degree of avatar self-representation has a direct effect on children's arousal, stress, focus, cognitive load, total body movement, and fatigue.

Correlational Evidence: Correlational evidence is the identification of the relationship between a condition or initiative and a specific outcome. When the results show correlations, these might be due to the intervention or another factor. The correlation results cannot answer "why" questions, yet they are still useful for arguing and hypothesizing about the potential impact of an intervention. In our systematic search, we identified twenty-eight papers that presented correlational evidence about the impact of an MMLA system. Those papers showed that students' multimodal behavioural engagement correlates with their performance on various outcome measures including, undergraduate students' final test performance (Ashwin \& Guddeti, 2019); effective gesture use in teaching sessions (Barmaki \& Hughes, 2018); recall competence in a vocabulary test ( Beardsley et al., 2018); science knowledge and group interactions (Anderson et al., 2016); content knowledge in microbiology (Emerson, Cloude, et al., 2020); Maths knowledge in (Liu et al., 2019); understanding of feedback loops (Andrade, 2017); exam grades in a physics course (Pijeira-Díaz et al., 2018); oral presentations (Roque et al., 2019); programming knowledge (Schneider, 2019); performance in engineering-related computer games (Gomes et al., 2013); problem-solving performance in mathematics (Chen et al., 2016; Oviatt \& Cohen, 2013); collaborative learning (Huang et al., 2019; Nakano et al., 2015; Olsen et al., 
2020; Reilly \& Schneider, 2019); design quality and learning gains in hands-on engineering tasks (Worsley et al., 2015; Worsley \& Blikstein, 2018, 2015); cognitive and affective aspects of tutorial dialogues (Vail et al., 2014); open-ended physical computing tasks (Spikol, Ruffaldi, Landolfi, et al., 2017); collaborative writing (Nöel et al., 2018); debate tutoring (Cukurova et al., 2019); learners' on-task engagement (behavioural, motivational, emotional) (Papamitsiou et al., 2020); collaborative problem-solving in virtual meetings (Vrzakova et al., 2020); metacognitive experiences (Dindar et al., 2020); and cognitive performance over diverse sets of cognitive tasks (Sharma, Niforatos, et al., 2020).

Descriptive Evidence: Descriptive evidence stems from the summary of characterizing individuals and groups who use MMLA tools and depicting events, processes, trends, or relationships that emerge from users' interaction with MMLA. This type of evidence can provide some insight into potential effectiveness; however, they are not considered as robust evidence of impact. Our systematic search revealed nine papers that provide some descriptive evidence about the impact of MMLA interventions to achieve educational outcomes. For instance, using an MMLA system, Oviatt (2013) found that domain experts were almost four times more likely to contribute correct solutions to group problems compared to non-experts. Similarly, J. Chen et al. (2016) showed that interest and confusion frequently occurred in learning a second language and that they are directly related to learning outcomes. In Boulton et al. (2018) the authors showed that fifteen out of seventeen tutors involved in the study have indicated that the MMLA system enabled the learners to achieve individual learning goals. Ochoa et al. (2018) reported that based on the individual interviews of nine randomly selected participants and questionnaires collected from 83 participants. Their results showed an overwhelmingly positive perception of the MMLA system, especially regarding perceived usefulness and feedback. Cornide-Reyes et al. (2019) found that the MMLA system's capacity to identify the intensity of productivity and effort of student contributions, as well as the predominant personality styles of students, helped teachers to differentiate the groups. Martin et al. (2019)used facial expressions to locate learning moments, their results showed that emotion tracking can reveal some important moments of learning that have been missed in the qualitative coding. Riquelme et al. (2019) found that their MMLA system allows them to find and visualize nontrivial information regarding interrelations between subjects in collaborative working groups. Similarly, Riquelme et al. (2020) used beacons to collect, analyze and visualize student geolocation data during collaborative tasks that involve movement and interactions through a library space. Based on the measured times of detection zones, the authors described three kinds of student roles: the collectors, the ambassadors, and the secretaries. Tan et al. (2020) presented a case study to explore students participation and engagement with two videos of different learning activities recorded from a 360-degree perspective. The authors found that data analyses such as heatmaps, view displays, and areas of interest along with user behaviour data extracted from the system helped them better describe how each student interacted with the two videos.

Anecdotal Evidence: Anecdotal evidence is evidence from personal statements or claims based on one or more people's personal experiences. When compared to other types of evidence, anecdotal evidence is generally regarded as limited in value due to several potential weaknesses regarding the evidence quality measurement values such 
as subjectivity. Therefore, it is hard to argue about the impact of MMLA using only this type of evidence. However, this type of evidence can be extremely valuable in the early stages of prototyping and user requirements/needs analysis studies of MMLA. We found twelve studies that present anecdotal evidence about the impact of an MMLA system on achieving an educational outcome. For instance, in Saquib et al. (2018), ten teachers who have been interviewed with regards to the system usefulness indicated that the system enabled them to gain deeper insight into their classroom. In MartinezMaldonado, Mangaroska, et al. (2020), 45-60 minutes of semi-structured interviews were collected from teachers related to their reflection about the visual representations of classroom positioning data visibility, awareness, and accountability. The results of the study found that teachers appreciated the visualization of their movement traces. In Martinez-Maldonado, Echeverria, et al. (2020), based on 45 minutes of interviews with eight educators and 30 minutes of focus groups with students of all teams, they found that teachers and students appreciated the layers of storytelling. Similarly, MMLA systems were anecdotally argued to have a positive impact on improving teacher reflection (Howard et al., 2019); to increase student interactions in distance learning settings (Yueh et al., 2014); to better guide students' reading behaviours (Huang et al., 2014); to help teachers better observe students conversations in problem-solving activities (Keskinarkaus et al., 2016); to provide real-time feedback in collocated collaboration (Praharaj et al., 2018); to assess the use of mobile mixed reality in health education (Birt et al., 2019); to increase the effective use of LA systems (MartinezMaldonado, Elliott, et al., 2020); to develop collaboration and problem-solving skills (Martinez-Maldonado et al., 2019); and to improve task performance (Abrahamson et al., 2016).

Machine Learning: Machine Learning provides evidence derived through prediction through the use of machine learning techniques, such as decision trees and neural networks. We identified nineteen papers that provided machine learning evidence on the outcome of an MMLA system. The papers cover a wide range of areas including predicting learning retention (Hwang et al., 2011); expertise and academic performance (Chango et al., 2019; Giannakos et al., 2019; Luz, 2013); performance in problem-solving in coding (Mangaroska et al., 2020); in Maths (Ochoa et al., 2013); in collaborative activities (Chejara et al., 2020; Schneider \& Blikstein, 2015); in openended project-based activities (Spikol et al., 2018; Spikol, Ruffaldi, \& Cukurova, 2017); in face-to-face collaborative problem-solving activities (Cukurova, Zhou, et al., 2020) and to predict students' dialogue acts (Ezen-Can et al., 2015) and oral presentation skills (Munoz et al., 2018). More from the teachers perspective, ML was used to process multimodal data to identify teachers' key instructional segments to assess their instruction (Donnelly et al., 2016) and to extract orchestration graphs including teaching activities and their social plane over time (Prieto et al., 2018). In addition, other studies focused on engagement to predict efficacious learning practices (Worsley, 2018), in the contexts of museums (Emerson, Henderson, et al., 2020); the context of an adaptive assessment platform (Sharma, Papamitsiou, et al., 2020) and learning with the internet of things (Camacho et al., 2020).

Proposing MMLA prototypes without specific evidence on impact: The search pointed to twenty-two studies that proposed MMLA prototypes, yet did not provide any specific evidence about the impact of the system on the expected educational outcomes. The papers cover a wide range of topics including classroom analytics for teacher 
orchestration (Prieto et al., 2016; Rodriguez Triana et al., 2017); group (Hsieh et al., 2010); reading comprehension (Lai et al., 2013); learner concentration (Su et al., 2013); teaching proficiency (Barmaki, 2015); improving students' talk-time and nonverbal behaviours in virtual classrooms (Barmaki \& Hughes, 2015); Maths learning from online platforms (Alyuz et al., 2017; Liu et al., 2018); healthcare training ( MartinezMaldonado et al., 2017); location analytics through proximity, location and motion data (Martinez-Maldonado et al., 2018); emotion and expression recognition (Deshmukh et al., 2018); collaborative (Noroozi et al., 2019); learning to dance salsa (Romano et al., 2019); to detect and resolve learning gaps in general (Tamura et al., 2019); predicting children's academic performance from games (Lee-Cultura, Sharma, \& Giannakos, 2020); to model learner behaviours in adaptive assessments (Sharma et al., 2019). Teacher gestures; cognitive, motivational and emotional aspects of science learning (Järvenoja et al., 2020); reflections on teaching practice (Eickholt, 2020) and gestures (Correa et al., 2020). Besides, Lew and Tang (2017) measured anxiety during EFL (English as a Foreign Language) essay writing with MMD from heart rate and galvanic skin response, but their results on educational outcomes were inconclusive and Beardsley et al. (2020) study focused on consent forms in MMLA research. Table.2 in Appendix D, summarizes the evidence of included papers. Fig.3 in Appendix E presents the distribution of papers per evidence type.

\subsection{Ethical Considerations Highlighted and Addressed in MMLA Research}

In this section, we address the second research question, which relates to the extent to which the papers identified in the SLR discuss the ethical considerations surrounding the design and use of their MMLA systems. thirteen papers have been identified to briefly discuss ethical considerations including privacy, consent of participants, data management issues, and ethical clearance from their home institute. In particular, Liu et al. (2019) noted that anonymized student IDs were stored on a secured research hard drive, but the paper did not clarify if the two-level data anonymization approach was adopted here or not to secure the students' privacy. Also, there were no ethical considerations regarding potential privacy concerns from the recorded pervasive data. Donnelly et al. (2016) captured audio recordings instead of video recordings because the former cause far fewer privacy concerns. However, the authors did not state any particular privacy concerns related to the use of video data in their research, for instance, the fact that students are more likely to be identified in a video compared to an audio recording. Keskinarkaus et al. (2016) suggested processing video and audio data and anonymizing the identity of the students in the future to allow the sharing and using of recorded clips in the discussion while preventing privacy violations. However, they did not discuss the details of the potential implications of these decisions. Martinez-Maldonado et al. (2019) recommended that consent recording strategies should be operationalized to address ethical and data privacy issues of small group collaboration analysis. Martinez-Maldonado et al. (2018) also highlighted that future work should explore the ethical issues that can emerge from MMLA. Similarly, Rodriguez Triana et al. (2017) raised an issue related to privacy and user traceability stating that GDPR requirements might lead future technology to generate only 
anonymous data, Martinez-Maldonado et al. (2017) recommended that issues related to privacy, consent, and data management should be considered when deploying learning analytics in real educational settings to produce sustainable strategies to handle these issues without stretching the classroom time; and Nöel et al. (2018) stated that participant's privacy has been protected by labelling the collected survey with identification codes (the number of the team they were in and the microphone they were using).

We were not able to find many studies that discuss the ethical implications of MMLA research from our first search. However, our second search covering papers from 2020 indicates that emerging studies appeared to be paying more attention to this dimension ${ }^{3}$. For instance, Martinez-Maldonado, Echeverria et al. (2020) stated that the analysis of their study was undertaken in a way that takes considerations with regards to ethical concerns around human accountability, algorithmic transparency and manipulability, risks from bias and errors and data privacy concerns into account. Additionally, the authors discussed data privacy issues such as data ownership, sharing, and deidentification in their discussions. Moreover, Martinez-Maldonado, Mangaroska et al. (2020) discussed some concerns around ethics, data privacy and pervasive surveillance. In their discussions, the potential impact of sharing instructional positioning data with other stakeholders on teachers' accountability was questioned as potential malpractice due to concerns about surveillance. Correa et al. (2020) mentioned that the procedure followed in their study has no privacy problems even if children have been recorded since the uploaded data is mainly OpenPose output files of students' skeletons without any faces and any revealing information from the students. Martinez-Maldonado, Elliott, et al. (2020) stated that the accountability questions presented in their paper including who should have access to the collected data, whether it should be available to the different roles including teachers, coordinators and students, can these data be used to assess the students' performance and how to protect students' privacy helped teachers to move beyond identification of privacy issues into the formulation of strategies to overcome these. Besides, a recent paper by Beardsley et al. (2020) introduced an informed consent comprehension test for MMLA research, that goes beyond the GDPR requirements and recognises the importance of students and teachers to be fully aware of the MMD they provide while they interact with MMLA systems. Their finding showed a low rate of enrolment as a result of the participant-oriented consent therefore, they suggested that more work need to be done to compromise this issue. However, none of the papers covered in this review specifically addressed the ethical issues or addressed the concerns raised, nor did any of the papers suggest systematic methods of mitigating potential unintended consequences. Instead, they appeared to indicate their possible concerns, the immediate need for ethics research in LA, and the suggestion that future research should be concentrated on the ethical implications of MMLA.

\footnotetext{
${ }^{3}$ This interpretive increase might be coincidental, noise, or indeed a trend, yet this would require further research investigations to be supported in the future.
} 


\section{Discussion}

One of the most influential essays in the history of law is the article written by Warren and Brandeis (1890) in Harvard Law Review, called "The Right to have privacy". This publication is regarded as the first in the United States to advocate a right to privacy, frequently referred to as humans' "right to be let alone". There is a clear lack of privacy definition. Although a unified definition of privacy in general, as well as a unified definition of privacy in learning analytics research environments, is elusive (Pardo \& Siemens, 2014), the ethical issues that emerge in the context of Learning Analytics and the need for a set of principles are of paramount importance. It is important to note that MMLA is different from LA in that MMLA involves capturing new high-frequency data for all human activity which can provide a more in-depth insight into the learning process (Blikstein, 2013), but may potentially be implemented in a highly intrusive manner (i.e face-recognition). However, since MMLA include data such as facial features, multiple dimensions of ethical considerations open up. Participants are more likely to be identified in MMLA compared to LA which relies mainly on the log data and clickstream. Therefore, are more prone to all key ethical issues highlighted above (privacy, transparency, fairness, accountability etc.).

The results presented above highlight the existing gap of robust impact evaluations and in-depth discussions of ethical considerations with regards to the design and use of MMLA in educational settings. Although 13 papers identified in this SLR briefly mentioned some aspects of the potential ethical challenges of working with MMD, they do not go beyond looking at the consent form advancements, universities' ethics regulation checkbox attempts, or a "brief lip-service" to the importance of ethics in research. What currently appears to be missing is an in-depth discussion about the ethical considerations that should be taken into account when MMD, some of which by nature are invasive such as EEG, skin conductors, some eye-tracking devices, are collected, processed, and visualised. Considerations of potential ethical and practical issues in the use of MMD are the first steps towards potentially hypothesising suggestions for feasible solutions to move forward. Therefore, in this section, we present a discussion of the relevant ethical considerations drawing examples from the broader areas of AI in Education and LA. These pointers can shape and encourage contributions from the community of MMLA researchers to help us move the discussion forward.

Within the last few years, thanks to the proliferation of AI research in general, there have been significant attempts to address the ethical challenges of AI implementations in social contexts. This research provides ideal starting points for MMLA researchers to initially address their current issues and extend upon them. Research covering the ethical considerations of AI range from general guidelines (Morley et al., 2019) to very specific checklists (Zook et al., 2017). More specific to Learning sciences (LS), Prinsloo and Slade (2013), provides a six principles framework for high education institutes taking a sociocritical approach. The framework has covered several important issues related to LA including 1- considering learning analytic as a moral practice to understand rather than measuring. 2- involving students as active agents and engaging them as collaborators, 3- students' performance and identity collected from LA should be kept for an agreed period of time, 4- LA is not enough to understand student success as learning is a non-linear process, 5- institutions should be transparent about the 
purpose of the data collection, who should have access to this data and what measures have been taken to protect students' identity, and 6- learning analytics provide a significant amount of data that Higher Education cannot afford not to use it, but should do it sustainably and ethically. Even though the framework was set out as a good start point towards ethical considerations of LA, it also has space for improvement to be used in MMLA research. First, as the proposed considerations have been designed for traditional LA, there is no particular focus on multimodal data collected from the physical spaces. This requires additional attention because most multimodal data (i.e EEG) and their collection and modelling techniques (i.e face recognition systems) by nature are more invasive than traditional keystroke and log data. Second, the framework does not address issues with more specific dimensions of ethical considerations such as accountability of the LA system decisions, fairness, equity and bias related to algorithmic predictions or the datasets. Finally, the proposed framework seems to be too broad to be easily applicable for practitioners, developers, and researchers of the MMLA field. For such purposes, a detailed checklist or guidance document might be more appropriate. For instance, Drachsler and Greller (2016) drew upon the experience of a large scale EU project and provided an eight-point checklist of ethical considerations named DELICATE. The checklist provides a practical and quick tool to check any data privacy issues that might arise along with the use of LA solutions. However, since the focus of this checklist was mainly on data privacy concerns including data collection, sharing, storing anonymization and transparency in data collection, from a broad ethical considerations point of view it may fall short. Similar points were also raised by Kitto and Knight (2019) who discussed the DELICATE checklist in their paper arguing for practical ethics for building LA solutions. Such broad considerations of ethics were recently discussed by Hakami and Hernandez-Leo (2020)'s review of their recent paper aiming to summarise the field's considerations on fairness, accountability, transparency, and human wellbeing. The paper has provided a valuable in-depth discussion about these concerns, the paper did not consider MMD and potential specific considerations of data from physical spaces. In addition, Johanes and Thille (2019) conducted interviews with technical infrastructure builders in higher education focusing on three themes including ubiquitous ethics. They suggested that the results can inform researchers, policymakers and infrastructure to better understand the building process and experience. In addition, the EU's General Data Protection Regulations (GDPR) also provide a general frame for any research that included human factors a recent publication (Beardsley et al., 2020) depicts the role and potential limitations of existing written consent forms (e.g., comprehension). However, as previous research suggests, such general guidance suggestions' effectiveness is very limited when it comes to the behaviour of technology professionals (McNamara et al., 2018). It becomes clear that developers, research and educational practitioners become frustrated by how little help is offered by highly abstract principles of AI ethics when it comes to their 'everyday practice at work' (Calvo \& Peters, 2019). Therefore, the general suggestions and key dimensions should be contextualised in specific research areas. However, as the SLR results reveal, the ethical aspects of MMLA research are rarely considered in publications.

At last but not least, in this review paper, we have used two existing frameworks, but appropriated and extended them accordingly to align them with the specifics of MMLA research. First, we built upon an impact evaluation framework that is generally 
applicable to educational technology evaluations and categorises evidence into anecdotal, descriptive, correlational, causal evidence (Cukurova \& Luckin, 2018). We added the types of evidence that are common for MMLA studies including iterative prototyping with no specific evidence on the impact and machine learning. Second, the framework for ethical dimensions, we adopted ACM's FAccT research (https://facctconference.org) involving fairness, accountability, and transparency. Here, we have extended it with considerations on privacy and bias as these dimensions are also frequently brought up as ethical concerns in learning analytics research and its relevant discussions. Both frameworks used in this paper can benefit future researchers and review studies to structure their findings and discussions.

\subsection{Limitations}

This is the first review paper that discusses the evidence of impact and ethical considerations with regard to the design and use of MMLA in educational settings. Although we adopted a systematic search considering all the major databases and following the steps set out by Kitchenham and Charters (2007), our work should be seen through the lens of some limitations. First, the methodological decisions (e.g., selection of databases, the search query) might introduce certain biases into the results. Second, the quality check and selection of the studies and their coding might pose another possible bias. However, the focus was clearly on the empirical evidence from the most eminent databases, and the coding of papers was performed by researchers with vast experience in learning analytics and learning technology. Third, some elements of the papers might not be described accurately or using different terminology. However, we extracted the needed information as accurately as possible. Fourth, we are aware that several publication venues do not require an ethical statement, therefore there might be ethical considerations that have been taken into consideration, but not properly reported to the published papers, and therefore this information is currently missing from our review. Fifth, we recognise that the search might have missed some system examples that support multimodality yet were positioned in areas that do not particularly focus on learning and/or analytics. The purpose of the present paper was to scan and report on the relevant literature from MMLA systems only, and not from other, broader research communities (i.e., affective computing or User Modeling Adaptation and Personalization (UMAP)), in which the term "multimodality" may be perceived from a different viewpoint, and the focus is not on the MMLA per se. Moreover, we recognize that different approaches, such as scoping review, narrative review, systematic mapping study or integrative review, might have also been employed and offer other benefits that serve valuable purposes (e.g., creating a map of a wide research field). Despite the limitations of our methodological decisions, the selected method and implementation adhered to is well-accepted and widely used in the area of learning technologies, providing certain assurance of the results.

\section{Conclusions}

The SLR showed that there is very limited reliable evidence showing the real-world impact of MMLA systems on educational outcomes. Most published research lacks 
strong causal evidence on the value of MMLA systems to improve educational outcomes. Perhaps more importantly, very few of the MMLA papers attempt to address key ethical issues within the context of MMLA. These issues of the lack of real-world impact and the lack of research regarding potential ethical concerns about the use of MMLA can to some extent be generalised to the LA field in general (Dawson et al., 2019; Ferguson \& Clow, 2017). However, MMD and more sophisticated methods used to analyse them in MMLA systems are likely to bring further complexities to be considered in these key dimensions. A recent work that stands out concerning the adoption was just published while finalizing this chapter (Dominguez et al., 2021). This work is one of the first (or as the authors argue, the first) that proposes, executes, and evaluates an MMLA application (an automated oral presentation feedback system) into an institution-wide setting. The authors provide a set of challenges with regards to technological, logistical, and pedagogical aspects, and highlight that for the MMLA application to be adopted, there are five important aspects: 1) instructors advocacy; 2) simple system; 3) good integration with the existing practices; 4) smooth logistics and 5) some positive evidence. Both, aspects one and three, require a value alignment in terms of ethical considerations between the practitioners and MMLA systems' design features. Moreover, aspect five highlights the need for impact evaluations of such systems in real-world settings and the important role of "positive evidence" to increase adoption.

However, the conclusions drawn from this systematic literature review should not encourage all MMLA researchers to focus on generating only quantifiable evidence or only causal evidence; or focus only on the ethical implications of their research. Different stages of MMLA development would benefit from different types of impact evaluations and different research expertise may be required to formulate and possibly address the ethical concerns of this research stream. In contrast to early prototypes where anecdotal and descriptive evidence can improve MMLA systems in early stages, mature solutions may require causal evidence to prove their value to educational researchers and practitioners. Our goal here is to highlight the lack of research generating causal evidence of impact and addressing the ethical implications of MMLA. For MMLA research to stay relevant and become part of mainstream education, future research should aim to address these gaps. 


\section{APPENDIX A}

\section{WOS}

- TS= (("multi*modal data" OR "multi*modal learning analytics" OR "Multi*modal* signal*" OR "multi*channel*" OR "sensing technolog*" OR "Gesture* Recog*" OR "multi*modal information*") AND (learn* OR acqui* OR Teach* OR interact*) AND ("Physical space*" OR "physical place*" OR "physical environment*" OR classroom* OR "physical space*" OR "physical analytics" OR "tangible interaction*") AND (dashboard OR tool* OR technolog*))

\section{Scopus}

TITLE-ABS-KEY ( ( "multimodal data" OR "multimodal learning analytics" OR "Multimodal* signal*" OR "multi*channel*" OR "sensing technolog*" OR "Gesture* Recog*" OR "multimodal information*" ) AND ( learn* OR acqui* OR teach* OR interact* ) AND ( "Physical spac*" OR "physical plac*" OR "physical environment*" OR classroom* OR "physical analytics" OR "tangible interaction*") AND (dashboard OR tool* OR technolog*))

ACM

AllField:( ("multimodal data" "multi modal data" "multimodal learning analytics" "multi modal learning analytics" "Multimodal signal" "Multi modal signal" multichannel "multi channel" "sensing technology" "sensing technologies" "Gestures Recognition" "multimodal information" "multi modal information") ) AND AllField:(( learn* acqui* Teach* interact*) ) AND AllField:(( "Physical space" "physical places" "physical environment" "physical environments" classroom "physical analytics" "tangible interaction") ) AND AllField:((dashboard OR tool* OR technolog* ))

\section{IEEE}

((("All Metadata": "multimodal data" OR "multi modal data" OR "multimodal learning analytics" OR "multi modal learning analytics" OR "Multimodal signal" OR "Multimodal signals" OR "Multi modal signals" OR "Multi modal signal" OR "multi channels" OR multichannel OR "multi channel" OR "multi channels" OR "sensing technology" OR "sensing technologies" OR "Gesture Recognition" OR "Gestures Recognition " OR "multimodal information" OR "multi modal information" OR "multi-modal informations" OR "multimodal informations" ) AND ( "All Metadata":learn* OR acqui* OR Teach* OR interact OR interaction ) AND ( "All Metadata": "Physical space" OR "Physical spaces" OR "physical place" OR "physical places" OR "physical environment" OR "physical environments" OR classroom OR "physical analytics" OR "tangible interaction" OR "tangible interactions") AND ( "All Metadata": dashboard OR tool* OR technolog*) )) 


\section{APPENDIX B}

Table 1. Overview of studies concerning their modality

\begin{tabular}{|c|c|c|}
\hline Modality & Measurements & References \\
\hline \multirow[t]{3}{*}{$\begin{array}{l}\text { Video } \\
\text { and audio }\end{array}$} & $\begin{array}{l}\text { Presenter's pose, } \\
\text { gaze direction, } \\
\text { visual attention }\end{array}$ & $\begin{array}{l}\text { Alyuz et al., 2017; Andrade, 2017; Boulton et al., } \\
\text { 2018; Cornide-Reyes et al., 2019; Huang et al., } \\
\text { 2014; Hwang et al., 2011; J. Chen et al., 2016; L. } \\
\text { Chen et al., 2016; Ochoa \& Dominguez, 2020; } \\
\text { Ochoa et al., 2018; Su et al., 2013; Tamura et al., } \\
\text { 2019; Tan et al., 2020; Worsley et al., 2015. }\end{array}$ \\
\hline & $\begin{array}{l}\text { Audio, dialogue's } \\
\text { characteristics }\end{array}$ & $\begin{array}{l}\text { Anderson et al., 2016; Boulton et al., 2018; } \\
\text { Chejara et al., 2020; Cornide-Reyes et al., 2020; } \\
\text { Cukurova et al., 2019; Donnelly et al., 2016; } \\
\text { Eickholt, 2020; Howard et al., 2019; } \\
\text { Järvenoja et al., 2020; Keskinarkaus et al., 2016; } \\
\text { L. Chen et al., 2016; Luz, 2013; Liu et al., 2019; } \\
\text { Liu et al., 2018; Martinez-Maldonado et al., } \\
\text { 2017;Martinez-Maldonado et al., 2019; Martinez- } \\
\text { Maldonado, Elliott, et al., 2020; Nakano et al., } \\
\text { 2015; Nöel et al., 2018; Ochoa \& Dominguez, } \\
\text { 2020; Ochoa et al., 2013; Ochoa et al., 2018; } \\
\text { Olsen et al., 2020; Oviatt \& Cohen, 2013; Oviatt } \\
\text { et al., 2015; Oviatt, 2013; Praharaj et al., 2018; } \\
\text { Prieto et al., 2018; Riquelme et al., 2019; } \\
\text { Sharma, Leftheriotis, et al., 2020; Spikol et al., } \\
\text { 2018; } \\
\text { Spikol, Ruffaldi, \& Cukurova, 2017; } \\
\text { Spikol, Ruffaldi, Landolfi, et al., 2017; } \\
\text { Vrzakova et al., 2020; Worsley \& Blikstein, } \\
\text { 2018; Worsley et al., 2015; Worsley, 2018; Yueh } \\
\text { et al., 2014. }\end{array}$ \\
\hline & $\begin{array}{l}\text { Facial data and } \\
\text { emotions }\end{array}$ & $\begin{array}{l}\text { Ahn \& Harley, 2020; Alyuz et al., 2017; Ashwin } \\
\text { \& Guddeti, 2019; Boulton et al., 2018; } \\
\text { Deshmukh et al., 2018; Emerson, Cloude, et al., } \\
\text { 2020; } \\
\text { Emerson, Henderson, et al., 2020; Giannakos et } \\
\text { al., 2019; J. Chen et al., 2016; Järvenoja et al., }\end{array}$ \\
\hline
\end{tabular}




\begin{tabular}{|c|c|c|}
\hline & & $\begin{array}{l}\text { 2020; Keskinarkaus et al., 2016; L. Chen et al., } \\
\text { 2016; Lee-Cultura, Sharma, \& Giannakos, 2020; } \\
\text { Lee-Cultura, Sharma, Papavlasopoulou, et al., } \\
\text { 2020; Mangaroska et al., 2020; Martin et al., } \\
\text { 2019; Liu et al., 2018; Papamitsiou et al., 2020; } \\
\text { Sharma, Niforatos, et al., 2020; Sharma, } \\
\text { Papamitsiou, et al., 2020; Vail et al., 2014; } \\
\text { Worsley et al., 2015; Yueh et al., 2014 . }\end{array}$ \\
\hline & $\begin{array}{l}\text { Posture and } \\
\text { gesture, body } \\
\text { movement, } \\
\text { distance, motion, } \\
\text { Position }\end{array}$ & $\begin{array}{l}\text { Andrade, 2017; Ashwin \& Guddeti, 2019; } \\
\text { Correa et al., 2020; Cukurova, Zhou, et al., 2020; } \\
\text { Howard et al., 2019; Keskinarkaus et al., 2016; } \\
\text { Ochoa et al., 2013; Oviatt \& Cohen, 2013; Oviatt } \\
\text { et al., 2015; Oviatt, 2013; Spikol et al., 2018; } \\
\text { Spikol, Ruffaldi, \& Cukurova, 2017;Spikol, } \\
\text { Ruffaldi, Landolfi, et al., 2017; Tamura et al., } \\
\text { 2019; Vrzakova et al., 2020; Vujovic et al., 2020. }\end{array}$ \\
\hline \multirow[t]{2}{*}{$\begin{array}{l}\text { Eye- } \\
\text { tracking }\end{array}$} & $\begin{array}{l}\text { Learners' } \\
\text { concentration } \\
\text { level, visual } \\
\text { attention and } \\
\text { habits }\end{array}$ & $\begin{array}{l}\text { Abrahamson et al., 2016; Ahn \& Harley, 2020; } \\
\text { Emerson, Cloude, et al., 2020; Emerson, } \\
\text { Henderson, et al., 2020; Giannakos et al., 2019; } \\
\text { Gomes et al., 2013; Huang et al., 2019; Lee- } \\
\text { Cultura, Sharma, \& Giannakos, 2020; Lee- } \\
\text { Cultura, Sharma, Papavlasopoulou, et al., 2020; } \\
\text { Mangaroska et al., 2020; Olsen et al., 2020; } \\
\text { Papamitsiou et al., 2020; Prieto et al., 2018; } \\
\text { Reilly \& Schneider, 2019; Schneider, 2019; } \\
\text { Sharma et al., 2019; Sharma, Papamitsiou, et al., } \\
\text { 2020; Tamura et al., 2019. }\end{array}$ \\
\hline & $\begin{array}{l}\text { Learners' gaze in } \\
\text { off-screen activity }\end{array}$ & $\begin{array}{l}\text { Nakano et al., 2015; Papavlasopoulou et al., } \\
2018 \\
\text { Prieto et al., 2016; Sharma, Leftheriotis, et al., } \\
2020 .\end{array}$ \\
\hline $\begin{array}{c}\text { Skin } \\
\text { sensing }\end{array}$ & $\begin{array}{c}\text { Student's } \\
\text { physiological } \\
\text { data, arousal and } \\
\text { EDA }\end{array}$ & $\begin{array}{l}\text { Dindar et al., 2020; Giannakos et al., 2019; } \\
\text { Hwang et al., 2011; J. Chen et al., 2016; } \\
\text { Järvenoja et al., 2020; Huang et al., 2019; Lee- } \\
\text { Cultura, Sharma, \& Giannakos, 2020; Lee- } \\
\text { Cultura, Sharma, Papavlasopoulou, et al., 2020; } \\
\text { Lew and Tang, 2017; Liu et al., 2018; } \\
\text { Mangaroska et al., 2020; Martinez-Maldonado et } \\
\text { al., 2018; Martinez-Maldonado, Echeverria, et } \\
\text { al. 2020; Martinez-Maldonado, Elliott, et al., } \\
\text { 2020; Noroozi et al., 2019; Papamitsiou et al., } \\
\text { 2020; Pijeira-Díaz et al., 2018; Reilly \& }\end{array}$ \\
\hline
\end{tabular}




\begin{tabular}{|c|c|c|}
\hline & & $\begin{array}{l}\text { Schneider, 2019; Schneider, 2019; Sharma, } \\
\text { Papamitsiou, et al., 2020; Tamura et al., 2019; } \\
\text { Worsley \& Blikstein, 2015; Worsley \& Blikstein, } \\
\text { 2018; Worsley et al., 2015. }\end{array}$ \\
\hline & $\begin{array}{l}\text { Students' } \\
\text { cognitive load }\end{array}$ & $\begin{array}{l}\text { Larmuseau et al., 2020; Sharma, NifoIn-deptht } \\
\text { al., 2020; }\end{array}$ \\
\hline $\begin{array}{l}\text { In depth } \\
\text { camera }\end{array}$ & $\begin{array}{l}\text { Posture and } \\
\text { gesture }\end{array}$ & $\begin{array}{l}\text { Barmaki \& Hughes, 2015; Barmaki \& Hughes, } \\
\text { 2018; Barmaki, 2015; Boulton et al., 2018; } \\
\text { Emerson, Henderson, et al., 2020; Ezen-Can et } \\
\text { al., 2015; Huang et al., 2019; Junokas et al., } \\
\text { 2018; Lee-Cultura, Sharma, \& Giannakos, 2020; } \\
\text { Lee-Cultura, Sharma, Papavlasopoulou, et al., } \\
\text { 2020; Martinez-Maldonado et al., 2017; } \\
\text { Martinez-Maldonado et al., 2019; Munoz et al., } \\
\text { 2018; Romano et al., 2019; Roque et al., 2019; } \\
\text { Schneider \& Blikstein, 2015; Schneider, 2019; } \\
\text { Spikol et al., 2018; Vail et al., 2014; Worsley \& } \\
\text { Blikstein, 2015; Worsley \& Blikstein, 2018; } \\
\text { Worsley et al., 2015; Worsley, 2018. }\end{array}$ \\
\hline $\begin{array}{c}\text { Location } \\
\text { sensing }\end{array}$ & $\begin{array}{l}\text { Location, position } \\
\text { and duration, } \\
\text { movement }\end{array}$ & $\begin{array}{l}\text { Camacho et al., 2020; Eickholt, 2020; Hsieh et } \\
\text { al., 2010; Martinez-Maldonado et al., 2018; } \\
\text { Martinez-Maldonado, Echeverria, et al. 2020; } \\
\text { Liu et al., 2018; Martinez-Maldonado, } \\
\text { Mangaroska, et al., 2020; Prieto et al., } \\
\text { 2016; Prieto et al., 2018; Reilly \& Schneider, } \\
\text { 2019; Riquelme et al., 2020; Saquib et al., 2018. }\end{array}$ \\
\hline $\begin{array}{l}\text { Pressure } \\
\text { sensing }\end{array}$ & Sitting position & Hwang et al., 2011; Su et al., 2013. \\
\hline $\begin{array}{l}\text { EEG } \\
\text { sensor }\end{array}$ & $\begin{array}{l}\text { EEG data, brain } \\
\text { activity }\end{array}$ & $\begin{array}{l}\text { Beardsley et al., 2018; Giannakos et al., 2019; } \\
\text { Papamitsiou et al., 2020; Prieto et al., } \\
\text { 2016; Sharma et al., 2019; Sharma, Papamitsiou, } \\
\text { et al., 2020; Tamura et al., 2019. }\end{array}$ \\
\hline
\end{tabular}




\section{APPENDIX $C$}

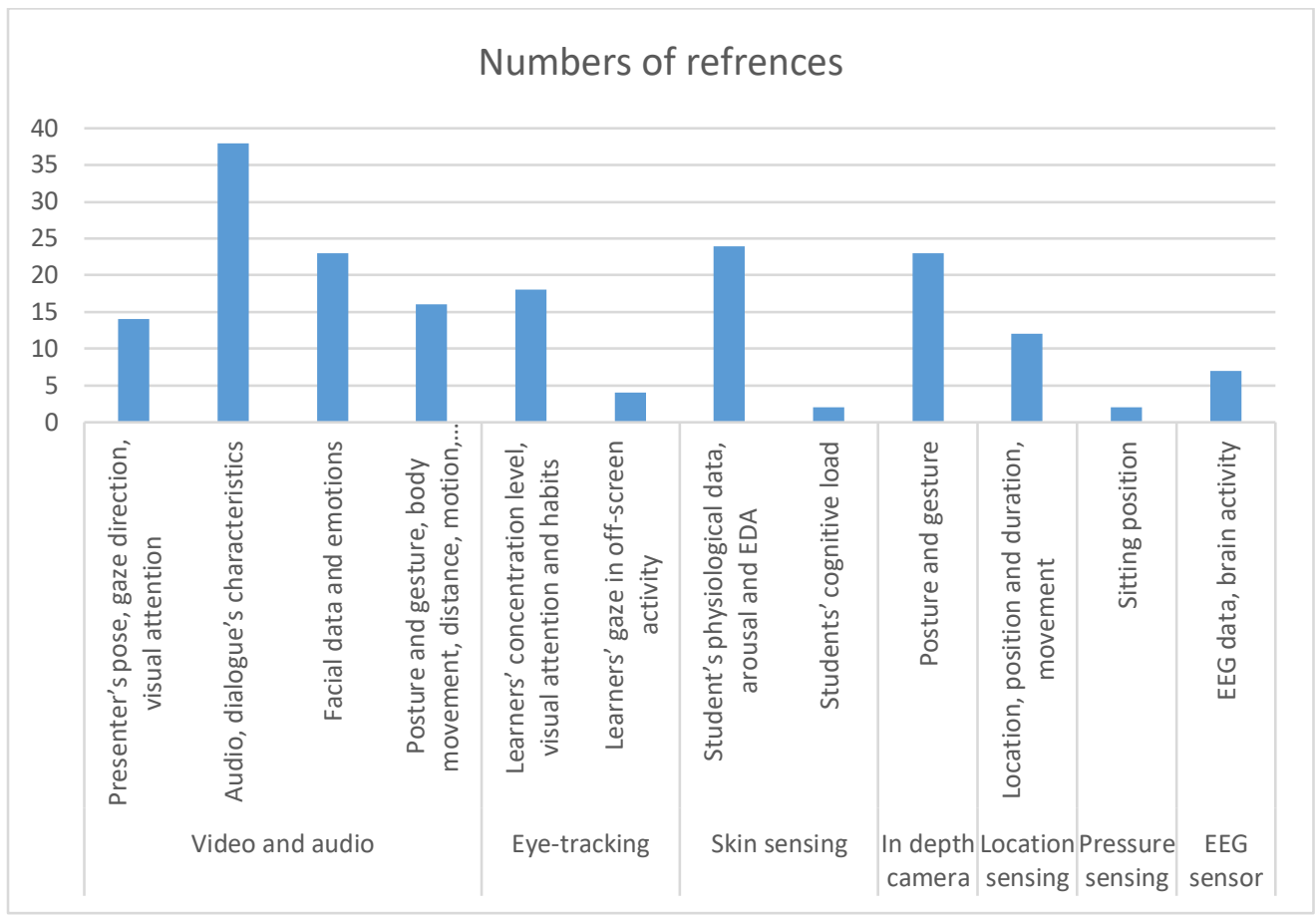

Fig. 2. The distribution of papers belonging to each modality category 


\section{APPENDIX D}

Table 2. Overview of studies concerning their evidence

\begin{tabular}{|c|c|}
\hline Evidence & References \\
\hline $\begin{array}{c}\text { Causal Evidence } \\
\text { (10) }\end{array}$ & $\begin{array}{l}\text { Ahn \& Harley, 2020; Cornide-Reyes et al., 2020; Junokas et } \\
\text { al., 2018; Larmuseau et al., 2020; Lee-Cultura, Sharma, } \\
\text { Papavlasopoulou, et al., 2020; Ochoa \& Dominguez, 2020; } \\
\text { Oviatt et al., 2015; Papavlasopoulou et al., } 2018 \text {; Sharma, } \\
\text { Leftheriotis, et al., 2020; Vujovic et al., 2020. }\end{array}$ \\
\hline $\begin{array}{l}\text { Correlational } \\
\text { Evidence (28) }\end{array}$ & $\begin{array}{l}\text { Anderson et al., 2016; Andrade, 2017; Ashwin \& Guddeti, } \\
\text { 2019; Barmaki \& Hughes, 2018; Beardsley et al., 2018; } \\
\text { Cukurova et al., 2019; Dindar et al., 2020; Emerson, } \\
\text { Cloude, et al., 2020; Gomes et al., 2013; Huang et al., 2019; } \\
\text { L. Chen et al., 2016; Liu et al., 2019; Nakano et al., 2015; } \\
\text { Nöel et al., 2018; Olsen et al., 2020; Oviatt \& Cohen, 2013; } \\
\text { Papamitsiou et al., 2020; Pijeira-Díaz et al., 2018; Sharma, } \\
\text { Niforatos, et al., 2020; Reilly \& Schneider, 2019; Roque et } \\
\text { al., 2019; Schneider, 2019; Spikol, Ruffaldi, Landolfi, et al., } \\
\text { 2017; } \\
\text { Vail et al., 2014; Vrzakova et al., 2020; Worsley \& } \\
\text { Blikstein, 2015; Worsley \& Blikstein, 2018; Worsley et al., } \\
\text { 2015. }\end{array}$ \\
\hline $\begin{array}{l}\text { Descriptive } \\
\text { Evidence (9) }\end{array}$ & $\begin{array}{l}\text { Boulton et al., } 2018 \text {; Cornide-Reyes et al., 2019; J. Chen et } \\
\text { al., 2016; Martin et al. 2019; Ochoa et al., 2018; Oviatt, } \\
\text { 2013; Riquelme et al., 2019; Riquelme et al., 2020; Tan et } \\
\text { al., 2020. }\end{array}$ \\
\hline $\begin{array}{c}\text { Anecdotal } \\
\text { Evidence (12) }\end{array}$ & $\begin{array}{l}\text { Abrahamson et al., 2016; Birt et al., 2019; Howard et al., } \\
\text { 2019; Keskinarkaus et al., 2016; Martinez-Maldonado et al., } \\
\text { 2019; Martinez-Maldonado, Elliott, et al., 2020; Martinez- } \\
\text { Maldonado, Echeverria, et al. 2020; Martinez-Maldonado, } \\
\text { Mangaroska, et al., 2020; Praharaj et al., 2018; Saquib et al., } \\
\text { 2018; Huang et al., 2014; Yueh et al., 2014. }\end{array}$ \\
\hline $\begin{array}{l}\text { Machine Learning } \\
\text { (19) }\end{array}$ & $\begin{array}{l}\text { Camacho et al., 2020; Chango et al., 2019; Chejara et al., } \\
\text { 2020; Cukurova, Zhou, et al., 2020; Spikol, Ruffaldi, \& } \\
\text { Cukurova, 2017; Donnelly et al., 2016; Emerson, } \\
\text { Henderson, et al., 2020; Ezen-Can et al., 2015; Giannakos et }\end{array}$ \\
\hline
\end{tabular}




\begin{tabular}{|c|c|}
\hline & $\begin{array}{l}\text { al., 2019; Hwang et al., 2011; Luz, 2013; Mangaroska et al., } \\
\text { 2020; Munoz et al., 2018; Ochoa et al., 2013; Prieto et al., } \\
\text { 2018; Schneider \& Blikstein, 2015; Sharma, Papamitsiou, et } \\
\text { al., 2020; Spikol et al., 2018; Worsley, 2018. }\end{array}$ \\
\hline $\begin{array}{l}\text { Proposing MMLA } \\
\text { prototypes with no } \\
\text { specific evidence } \\
\text { on impact }(22)\end{array}$ & $\begin{array}{l}\text { Alyuz et al., 2017; Barmaki \& Hughes, 2015; Barmaki, } \\
\text { 2015; Beardsley et al. 2020; Deshmukh et al., 2018; } \\
\text { Eickholt, 2020; Correa et al., 2020; Hsieh et al., 2010; } \\
\text { Järvenoja et al., 2020; Lai et al., 2013 ; Lee-Cultura, } \\
\text { Sharma, \& Giannakos, 2020; Lew and Tang, 2017; Liu et } \\
\text { al., 2018; Martinez-Maldonado et al., 2017; Martinez- } \\
\text { Maldonado et al., 2018; Noroozi et al., 2019; Prieto et al., } \\
\text { 2016; Rodriguez Triana et al., 2017; Romano et al., 2019; } \\
\text { Sharma et al., 2019; Su et al., 2013; Tamura et al., 2019. }\end{array}$ \\
\hline
\end{tabular}




\section{APPENDIX E}

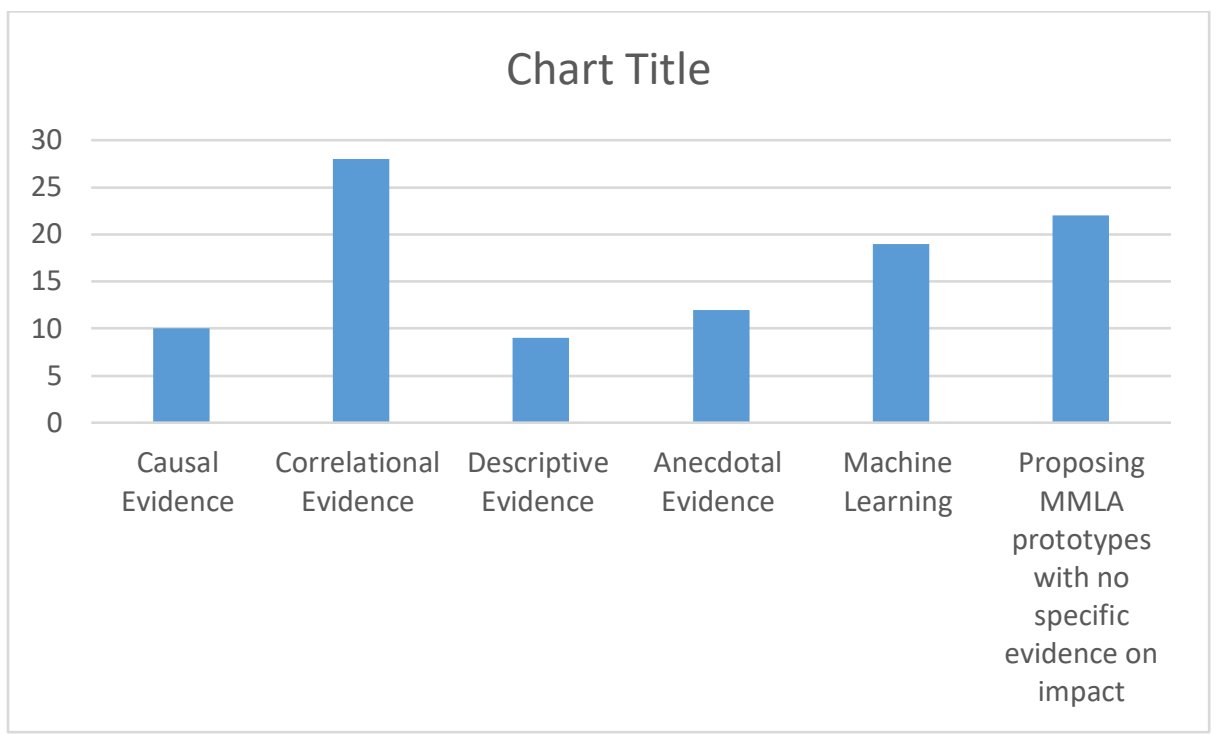

Fig. 3. The distribution of papers per evidence type 


\section{References}

1. Abdi, S., Khosravi, H., Sadiq, S., \& Gasevic, D. (2020). Complementing educational recommender systems with open learner models. Proceedings of the Tenth International Conference on Learning Analytics \& Knowledge, 360-365. https://doi.org/10.1145/3375462.3375520

2. Abrahamson, D., Shayan, S., Bakker, A., \& Van Der Schaaf, M. (2016). Eye-Tracking Piaget: Capturing the Emergence of Attentional Anchors in the Coordination of Proportional Motor Action. Human Development, 58(4-5), 218-224. Scopus. https://doi.org/10.1159/000443153

3. Ahn, B. “Tony," \& Harley, J. M. (2020). Facial expressions when learning with a Queer History App: Application of the Control Value Theory of Achievement Emotions. British Journal of Educational Technology, 51(5), 1563-1576. https://doi.org/10.1111/bjet.12989

4. Alyuz, N., Okur, E., Genc, U., Aslan, S., Tanriover, C., \& Esme, A. A. (2017). An unobtrusive and multimodal approach for behavioral engagement detection of students. In Bianchi-Berthouze N., Baud-Bovy G., Volta E., Volpe G., Gori M., \& Alborno P. (Eds.), MIE - Proc. ACM SIGCHI Int. Workshop Multimodal Interact. Educ., Co-located ICMI (Vols. 2017-November, pp. 26-32). Association for Computing Machinery, Inc; Scopus. https://doi.org/10.1145/3139513.3139521

5. Anderson, C. G., Binzak, J. V., Dalsen, J., Saucerman, J., Jordan-Douglass, A., Kumar, V., Turker, A., Berland, M., Squire, K., \& Steinkuehler, C. (2016). Situating Deep Multimodal Data on Game-Based STEM Learning. In Looi, C. K., Polman, J. L., Cress, U., and Reimann, P. (Eds.). Transforming Learning, Empowering Learners: The International Conference of the Learning Sciences (ICLS), 2, 974-977. Singapore: International Society of the Learning Sciences

6. Andrade, A. (2017). Understanding student learning trajectories using multimodal learning analytics within an embodied-interaction learning environment. Proceedings of the Seventh International Learning Analytics \& Knowledge Conference, 70-79. https://doi.org/10.1145/3027385.3027429

7. Andrejevic, M., \& Selwyn, N. (2020). Facial recognition technology in schools: Critical questions and concerns. Learning, Media and Technology, 45(2), 115-128. https://doi.org/10.1080/17439884.2020.1686014

8. Ashwin, T. S., \& Guddeti, R. M. R. (2019). Unobtrusive Behavioral Analysis of Students in Classroom Environment Using Non-Verbal Cues. IEEE Access, 7, 150693-150709. https://doi.org/10.1109/ACCESS.2019.2947519

9. Barmaki, R. (2015). Multimodal Assessment of Teaching Behavior in Immersive Rehearsal Environment-TeachLivE. Proceedings of the 2015 ACM on International Conference on Multimodal Interaction, 651-655. https://doi.org/10.1145/2818346.2823306

10. Barmaki, R., \& Hughes, C. E. (2015, November). Providing real-time feedback for student teachers in a virtual rehearsal environment. In Proceedings of the 2015 ACM on International Conference on Multimodal Interaction. 531537. https://doi.org/10.1145/2818346.2830604

11. Barmaki, R., \& Hughes, C. E. (2018). Embodiment analytics of practicing teachers in a virtual immersive environment. Journal of Computer Assisted Learning, 34(4), 387-396. https://doi.org/10.1111/jcal.12268

12. Beardsley, M., Hernández-Leo, D., \& Ramirez-Melendez, R. (2018). Seeking reproducibility: Assessing a multimodal study of the testing effect. Journal of Computer Assisted Learning, 34(4), 378-386. https://doi.org/10.1111/jcal.12265 
13. Beardsley, M., Moreno, J. M., Vujovic, M., Santos, P., \& Hernández-Leo, D. (2020). Enhancing consent forms to support participant decision making in multimodal learning data research. British Journal of Educational Technology, 51(5), 1631-1652. https://doi.org/10.1111/bjet.12983

14. Birt, J., Clare, D., \& Cowling, M. (2019). Piloting Multimodal Learning Analytics using Mobile Mixed Reality in Health Education. 2019 IEEE 7th International Conference on Serious Games and Applications for Health (SeGAH), 1-6. https://doi.org/10.1109/SeGAH.2019.8882435

15. Blikstein, P. (2013). Multimodal learning analytics. Proceedings of the Third International Conference on Learning Analytics and Knowledge, 102-106. https://doi.org/10.1145/2460296.2460316

16. Blikstein, P., \& Worsley, M. (2016). Multimodal Learning Analytics and Education Data Mining: Using computational technologies to measure complex learning tasks. Journal of Learning Analytics, 3(2), 220-238. https://doi.org/10.18608/jla.2016.32.11

17. Boulton, H., Brown, D., Standen, P., Belmonte, M., Kwiatkowska, G., Hughes-Roberts, T., \& Taheri, M. (2018, March). Multi-modalities in classroom learning environments. In INTED2018 Proceedings: 12th Annual International Technology, Education and Development Conference. 1542-1547. Valencia, Spain: IATED Academy.

18. Calvo, R. A., \& Peters, D. (2019). Design for Wellbeing-Tools for Research, Practice and Ethics. Extended Abstracts of the 2019 CHI Conference on Human Factors in Computing Systems, 1-5. https://doi.org/10.1145/3290607.3298800

19. Camacho, V. L., Guía, E. d l, Olivares, T., Flores, M. J., \& Orozco-Barbosa, L. (2020). Data Capture and Multimodal Learning Analytics Focused on Engagement With a New Wearable IoT Approach. IEEE Transactions on Learning Technologies, 13(4), 704-717. https://doi.org/10.1109/TLT.2020.2999787

20. Chango, W., Cerezo, R., \& Romero, C. (2019). Predicting academic performance of university students from multi-sources data in blended learning. Proceedings of the Second International Conference on Data Science, E-Learning and Information Systems, 1-5. https://doi.org/10.1145/3368691.3368694

21. Chejara, P., Prieto, L., Ruiz-Calleja, A., Rodríguez-Triana, M., Shankar, S. K., \& Kasepalu, R. (2020). Quantifying Collaboration Quality in Face-to-Face Classroom Settings Using MMLA (pp. 159-166). https://doi.org/10.1007/978-3-030-58157-2_11

22. Chen, L., Li, X., Xia, Z., Song, Z., Morency, L. P., \& Dubrawski, A. (2016). Riding an Emotional Roller-Coaster: A Multimodal Study of Young Child's Math Problem Solving Activities. International Educational Data Mining Society.

23. Chen, L., Li, X., \& Xia, Z. (2016). Riding an emotional roller-coaster: A multimodal study of young child's math problem solving activities. 8.

24. Chua, Y. H. V., Dauwels, J., \& Tan, S. C. (2019). Technologies for automated analysis of co-located, real-life, physical learning spaces: Where are we now? Proceedings of the 9th International Conference on Learning Analytics \& Knowledge - LAK19, 11-20. https://doi.org/10.1145/3303772.3303811

25. Connolly, P., Keenan, C., \& Urbanska, K. (2018). The trials of evidence-based practice in education: A systematic review of randomised controlled trials in education research 1980-2016. Educational Research, 60(3), 276-291. https://doi.org/10.1080/00131881.2018.1493353

26. Cornide-Reyes, H., Noël, R., Riquelme, F., Gajardo, M., Cechinel, C., Mac Lean, R., ... \& Munoz, $R$. (2019). Introducing low-cost sensors into the classroom settings: Improving the assessment in agile practices with multimodal learning analytics. Sensors, 19(15), 3291. 
27. Cornide-Reyes, H., Riquelme, F., Monsalves, D., Noel, R., Cechinel, C., Villarroel, R., Ponce, F., \& Munoz, R. (2020). A multimodal real-time feedback platform based on spoken interactions for remote active learning support. Sensors (Switzerland), 20(21), 127. Scopus. https://doi.org/10.3390/s20216337

28. Crescenzi-Lanna, L. (2020). Multimodal Learning Analytics research with young children: A systematic review. British Journal of Educational Technology, 51(5), 1485-1504. https://doi.org/10.1111/bjet.12959

29. Cukurova, M., Giannakos, M., \& Martinez-Maldonado, R. (2020). The promise and challenges of multimodal learning analytics. British Journal of Educational Technology, 51(5), 1441-1449. https://doi.org/10.1111/bjet.13015

30. Cukurova, M., Kent, C., \& Luckin, R. (2019). Artificial intelligence and multimodal data in the service of human decision-making: A case study in debate tutoring. British Journal of Educational Technology, 50(6), 3032-3046. https://doi.org/10.1111/bjet.12829

31. Cukurova, M., \& Luckin, R. (2018). Measuring the Impact of Emerging Technologies in Education: A Pragmatic Approach. Second Handbook of Information Technology in Primary and Secondary Education, 1181-1199. https://doi.org/10.1007/978-3-319-710549_81

32. Cukurova, M., Zhou, Q., Spikol, D., \& Landolfi, L. (2020). Modelling collaborative problem-solving competence with transparent learning analytics: Is video data enough? Proceedings of the Tenth International Conference on Learning Analytics \& Knowledge, 270-275. https://doi.org/10.1145/3375462.3375484

33. Dawson, S., Joksimovic, S., Poquet, O., \& Siemens, G. (2019). Increasing the Impact of Learning Analytics. Proceedings of the 9th International Conference on Learning Analytics \& Knowledge, 446-455. https://doi.org/10.1145/3303772.3303784

34. de Quincey, E., Briggs, C., Kyriacou, T., \& Waller, R. (2019). Student Centred Design of a Learning Analytics System. Proceedings of the 9th International Conference on Learning Analytics \& Knowledge, 353-362. https://doi.org/10.1145/3303772.3303793

35. Deshmukh, S. P., Patwardhan, M. S., \& Mahajan, A. R. (2018). Feedback Based Real Time Facial and Head Gesture Recognition for e-Learning System. Proceedings of the ACM India Joint International Conference on Data Science and Management of Data, 360-363. https://doi.org/10.1145/3152494.3167991

36. Di Mitri, D., Schneider, J., Specht, M., \& Drachsler, H. (2018). From signals to knowledge: A conceptual model for multimodal learning analytics. Journal of Computer Assisted Learning, 34, 338-349. https://doi.org/10.1111/jcal.12288

37. Dindar, M., Järvelä, S., \& Haataja, E. (2020). What does physiological synchrony reveal about metacognitive experiences and group performance? British Journal of Educational Technology, 51(5), 1577-1596. https://doi.org/10.1111/bjet.12981

38. Dominguez, F., Ochoa, X., Zambrano, D., Camacho, K., \& Castells, J. (2021). Scaling and Adopting a Multimodal Learning Analytics Application in an Institution-Wide Setting. IEEE Transactions on Learning Technologies, 1-1. https://doi.org/10.1109/TLT.2021.3100778

39. Donnelly, P. J., Blanchard, N., Samei, B., Olney, A. M., Sun, X., Ward, B., Kelly, S., Nystrand, M., \& D'Mello, S. K. (2016). Multi-sensor Modeling of Teacher Instructional Segments in Live Classrooms. Proceedings of the 18th ACM International Conference on Multimodal Interaction, 177-184. https://doi.org/10.1145/2993148.2993158

40. Doroudi, S., \& Brunskill, E. (2019). Fairer but Not Fair Enough On the Equitability of Knowledge Tracing. Proceedings of the 9th International Conference on Learning Analytics \& Knowledge, 335-339. https://doi.org/10.1145/3303772.3303838 
41. Drachsler, H., \& Greller, W. (2016). Privacy and analytics: It's a DELICATE issue a checklist for trusted learning analytics. Proceedings of the Sixth International Conference on Learning Analytics \& Knowledge - LAK '16, 89-98. https://doi.org/10.1145/2883851.2883893

42. Drachsler, H., \& Schneider, J. (2018). JCAL Special Issue on Multimodal Learning Analytics. Journal of Computer Assisted Learning, 34(4), 335-337. https://doi.org/10.1111/jcal.12291

43. Duval, E. (2011). Attention please!: Learning analytics for visualization and recommendation. Proceedings of the 1st International Conference on Learning Analytics and Knowledge - LAK '11, 9-17. https://doi.org/10.1145/2090116.2090118

44. Eickholt, J. (2020). Supporting Instructor Reflection on Employed Teaching Techniques via Multimodal Instructor Analytics. 2020 IEEE Frontiers in Education Conference (FIE), 1-5. https://doi.org/10.1109/FIE44824.2020.9273968

45. Emerson, A., Cloude, E. B., Azevedo, R., \& Lester, J. (2020). Multimodal learning analytics for game-based learning. British Journal of Educational Technology, 51(5), 1505-1526. https://doi.org/10.1111/bjet.12992

46. Emerson, A., Henderson, N., Rowe, J., Min, W., Lee, S., Minogue, J., \& Lester, J. (2020). Early Prediction of Visitor Engagement in Science Museums with Multimodal Learning Analytics. Proceedings of the 2020 International Conference on Multimodal Interaction, 107-116. https://doi.org/10.1145/3382507.3418890

47. Ezen-Can, A., Grafsgaard, J. F., Lester, J. C., \& Boyer, K. E. (2015). Classifying student dialogue acts with multimodal learning analytics. Proceedings of the Fifth International Conference on Learning Analytics And Knowledge, 280-289. https://doi.org/10.1145/2723576.2723588

48. Ferguson, R., \& Clow, D. (2017). Where is the evidence? A call to action for learning analytics. Proceedings of the Seventh International Learning Analytics \& Knowledge Conference, 56-65. https://doi.org/10.1145/3027385.3027396

49. Giannakos, M. N., Sharma, K., Pappas, I. O., Kostakos, V., \& Velloso, E. (2019). Multimodal data as a means to understand the learning experience. International Journal of Information Management, 48, 108-119. https://doi.org/10.1016/j.ijinfomgt.2019.02.003

50. Gibson, A., \& Lang, C. (2018). The pragmatic maxim as learning analytics research method. Proceedings of the 8th International Conference on Learning Analytics and Knowledge, 461-465. https://doi.org/10.1145/3170358.3170384

51. Gomes, J., Yassine, M., Worsley, M., \& Blikstein, P. (2013). Analysing Engineering Expertise of High School Students Using Eye Tracking and Multimodal Learning Analytics. In Educational Data Mining 2013.

52. Hakami, E., \& Hernández-Leo, D. (2020). How are Learning Analytics Considering the Societal Values of Fairness, Accountability, Transparency and Human Well-being? - A Literature Review. In: Martínez-Monés A, Álvarez A, Caeiro-Rodríguez M, Dimitriadis Y, editors. LASI-SPAIN 2020: Learning Analytics Summer Institute Spain 2020: Learning Analytics. Time for Adoption?; 2020 Jun 15-16; Valladolid, Spain. Aachen: CEUR; 2020. p. 121-41.

53. Correa, J., Farsani, D., \& Araya, R. (2020). An Application of Machine Learning and Image Processing to Automatically Detect Teachers' Gestures. In M. Hernes, K. Wojtkiewicz, \& E. Szczerbicki (Eds.), Advances in Computational Collective Intelligence (pp. 516-528). Springer International Publishing. https://doi.org/10.1007/978-3-03063119-2_42

54. Hoel, T., Griffiths, D., \& Chen, W. (2017). The influence of data protection and privacy frameworks on the design of learning analytics systems. Proceedings of the Seventh 
International Learning Analytics \& Knowledge Conference, 243-252. https://doi.org/10.1145/3027385.3027414

55. Howard, S. K., Yang, J., Ma, J., Ritz, C., Zhao, J., \& Wynne, K. (2019). Using Data Mining and Machine Learning Approaches to Observe Technology-Enhanced Learning. In Lee M.J.W., Nikolic S., Wong G.K.W., Shen J., Ros M., Lei L.C.U., \& Venkatarayalu N. (Eds.), Proc. IEEE Int. Conf. Teach., Assess., Learn. Eng., TALE (pp. 788-793). IEEE; Scopus. https://doi.org/10.1109/TALE.2018.8615443

56. Hsieh, J.-C., Chen, C.-M., \& Lin, H.-F. (2010). Social interaction mining based on wireless sensor networks for promoting cooperative learning performance in classroom learning environment. IEEE Int. Conf. Wirel., Mob. Ubiquitous Technol. Educ., WMUTE: Mob. Soc. Media Learn. Educ. Form. Informal Settings, 219-221.

https://doi.org/10.1109/WMUTE.2010.22

57. Huang, K., Bryant, T., \& Schneider, B. (2019). Identifying Collaborative Learning States Using Unsupervised Machine Learning on Eye-Tracking, Physiological and Motion Sensor Data. In International Educational Data Mining Society. International Educational Data Mining Society. https://eric.ed.gov/?id=ED599214

58. Huang, Y.-M., Hsu, C.-C., Su, Y.-N., \& Liu, C.-J. (2014). Empowering Classroom Observation with an E-Book Reading Behavior Monitoring System Using Sensing Technologies. Interacting with Computers, 26(4), 372-387. https://doi.org/10.1093/iwc/iwu012

59. Jan-Pan Hwang, Ting-Ting Wu, Fu-Jou Lai, \& Y. Huang. (2011). A sensor-assisted model for estimating the accuracy of learning retention in computer classroom. 2011 Fifth International Conference on Sensing Technology, 650-654. https://doi.org/10.1109/ICSensT.2011.6137063

60. Järvenoja, H., Malmberg, J., Törmänen, T., Mänty, K., Haataja, E., Ahola, S., \& Järvelä, S. (2020). A Collaborative Learning Design for Promoting and Analyzing Adaptive Motivation and Emotion Regulation in the Science Classroom. Frontiers in Education, 5. Scopus. https://doi.org/10.3389/feduc.2020.00111

61. Johanes, P., \& Thille, C. (2019). The heart of educational data infrastructures $=$ Conscious humanity and scientific responsibility, not infinite data and limitless experimentation. British Journal of Educational Technology, 50(6), 2959-2973. https://doi.org/10.1111/bjet.12862

62. Junokas, M. J., Lindgren, R., Kang, J., \& Morphew, J. W. (2018). Enhancing multimodal learning through personalized gesture recognition. Journal of Computer Assisted Learning, 34(4), 350-357. https://doi.org/10.1111/jcal.12262

63. Keskinarkaus, A., Huttunen, S., Siipo, A., Holappa, J., Laszlo, M., Juuso, I., Väyrynen, E., Heikkilä, J., Lehtihalmes, M., Seppänen, T., \& Laukka, S. (2016). MORE - a multimodal observation and analysis system for social interaction research. Multimedia Tools and Applications, 75(11), 6321-6345. Scopus. https://doi.org/10.1007/s11042-015-2574-9

64. Kitchenham, B., \& Charters, S. (2007). Guidelines for performing Systematic Literature Reviews in Software Engineering.

65. Kitto, K., \& Knight, S. (2019). Practical ethics for building learning analytics. British Journal of Educational Technology, 50(6), 2855-2870. https://doi.org/10.1111/bjet.12868

66. Knight, S., Anderson, T., \& Tall, K. (2017). Dear learner: Participatory visualisation of learning data for sensemaking. Proceedings of the Seventh International Learning Analytics \& Knowledge Conference, 532-533. https://doi.org/10.1145/3027385.3029443

67. Knox, J., Williamson, B., \& Bayne, S. (2020). Machine behaviourism: Future visions of 'learnification' and 'datafication' across humans and digital technologies. Learning, Media and Technology, 45(1), 31-45. https://doi.org/10.1080/17439884.2019.1623251 
68. Lai, C.-H., Pan, L.-C., Hsu, C.-C., Su, Y.-N., Jeng, Y.-L., Liu, C.-J., \& Huang, Y.-M. (2013). Develop a reading tracking function on e-book reading system by using sensing and cloudized storage technologies. Proc. Int. Conf. Sens. Technol., ICST, 356-360. Scopus. https://doi.org/10.1109/ICSensT.2013.6727674

69. Larmuseau, C., Cornelis, J., Lancieri, L., Desmet, P., \& Depaepe, F. (2020). Multimodal learning analytics to investigate cognitive load during online problem solving. British Journal of Educational Technology, 51(5), 1548-1562. https://doi.org/10.1111/bjet.12958

70. Lee-Cultura, S., Sharma, K., \& Giannakos, M. (2020). Using Multimodal Learning Analytics to Explore how Children Experience Educational Motion-Based Touchless Games. CEUR Workshop Proceedings.

71. Lee-Cultura, S., Sharma, K., Papavlasopoulou, S., Retalis, S., \& Giannakos, M. (2020). Using sensing technologies to explain children's self-representation in motion-based educational games. Proceedings of the Interaction Design and Children Conference, 541555. https://doi.org/10.1145/3392063.3394419

72. Lew, L., \& Tang, T. Y. (2017). "Beyond EFL Writing Anxiety”: Tapping into the Individual Emotionality of Proficient EFL Writers Through Semi-structured Analysis and Wearable Sensing Technology. In Zaphiris, $P$ and Ioannou, A (Ed.), LEARNING AND COLLABORATION TECHNOLOGIES: TECHNOLOGY IN EDUCATION, LCT 2017, PT II (Vol. 10296, pp. 170-181). https://doi.org/10.1007/978-3-319-58515-4_14

73. Liu, R., Stamper, J., Davenport, J., Crossley, S., McNamara, D., Nzinga, K., \& Sherin, B. (2019). Learning linkages: Integrating data streams of multiple modalities and timescales. Journal of Computer Assisted Learning, 35(1), 99-109. https://doi.org/10.1111/jcal.12315

74. Liu, S., Chen, Y., Huang, H., Xiao, L., \& Hei, X. (2018). Towards Smart Educational Recommendations with Reinforcement Learning in Classroom. 2018 IEEE International Conference on Teaching, Assessment, and Learning for Engineering (TALE), 1079-1084. https://doi.org/10.1109/TALE.2018.8615217

75. Luz, S. (2013). Automatic identification of experts and performance prediction in the multimodal math data corpus through analysis of speech interaction. Proceedings of the 15th ACM on International Conference on Multimodal Interaction, 575-582. https://doi.org/10.1145/2522848.2533788

76. Mangaroska, K., \& Giannakos, M. (2019). Learning Analytics for Learning Design: A Systematic Literature Review of Analytics-Driven Design to Enhance Learning. IEEE Transactions on Learning Technologies, 12(4), 516-534. https://doi.org/10.1109/TLT.2018.2868673

77. Mangaroska, K., Sharma, K., Gasevic, D., \& Giannakos, M. (2020). Multimodal Learning Analytics to Inform Learning Design: Lessons Learned from Computing Education. Journal of Learning Analytics, 7(3), 79-97. https://doi.org/10.18608/jla.2020.73.7

78. Martin, K., Wang, E. Q., Bain, C., \& Worsley, M. (2019). Computationally Augmented Ethnography: Emotion Tracking and Learning in Museum Games. In B. Eagan, M. Misfeldt, \& A. Siebert-Evenstone (Eds.), Advances in Quantitative Ethnography (Vol. 1112, pp. 141-153). Springer International Publishing. https://doi.org/10.1007/978-3-03033232-7_12

79. Martinez-Maldonado, R., Echeverria, V., Fernandez Nieto, G., \& Buckingham Shum, S. (2020). From Data to Insights: A Layered Storytelling Approach for Multimodal Learning Analytics. In Proceedings of the 2020 CHI Conference on Human Factors in Computing Systems (pp. 1-15). ACM. https://doi.org/10.1145/3313831.3376148

80. Martinez-Maldonado, R., Echeverria, V., Santos, O. C., Santos, A. D. P. D., \& Yacef, K. (2018). Physical learning analytics: A multimodal perspective. Proceedings of the 8th 
International Conference on Learning Analytics and Knowledge, 375-379. https://doi.org/10.1145/3170358.3170379

81. Martinez-Maldonado, R., Elliott, D., Axisa, C., Power, T., Echeverria, V., \& Shum, S. B. (2020). Designing translucent learning analytics with teachers: An elicitation process. Interactive Learning Environments, $0(0), 1-15$. https://doi.org/10.1080/10494820.2019.1710541

82. Martinez-Maldonado, R., Kay, J., Buckingham Shum, S., \& Yacef, K. (2019). Collocated Collaboration Analytics: Principles and Dilemmas for Mining Multimodal Interaction Data. Human-Computer Interaction, 34(1), 1-50. Scopus. https://doi.org/10.1080/07370024.2017.1338956

83. Martinez-Maldonado, R., Mangaroska, K., Schulte, J., Elliott, D., Axisa, C., \& Shum, S. B. (2020). Teacher Tracking with Integrity: What Indoor Positioning Can Reveal About Instructional Proxemics. Proceedings of the ACM on Interactive, Mobile, Wearable and Ubiquitous Technologies, 4(1), 1-27. https://doi.org/10.1145/3381017

84. Martinez-Maldonado, R., Power, T., Hayes, C., Abdiprano, A., Vo, T., Axisa, C., \& Buckingham Shum, S. (2017). Analytics Meet Patient Manikins: Challenges in an Authentic Small-group Healthcare Simulation Classroom. Proceedings of the Seventh International Learning Analytics \&\#38; Knowledge Conference, 90-94. https://doi.org/10.1145/3027385.3027401

85. Matcha, W., Ahmad Uzir, N., Gasevic, D., \& Pardo, A. (2019). A Systematic Review of Empirical Studies on Learning Analytics Dashboards: A Self-Regulated Learning Perspective. IEEE Transactions on Learning Technologies, 1-1. https://doi.org/10.1109/TLT.2019.2916802

86. McCarthy, J. (1960). Recursive functions of symbolic expressions and their computation by machine, part I. Communications of the ACM, 3(4), 184-195.

87. McNamara, A., Smith, J., \& Murphy-Hill, E. (2018, October). Does ACM's code of ethics change ethical decision making in software development?. In Proceedings of the 201826 th ACM joint meeting on european software engineering conference and symposium on the foundations of software engineering ( $\mathrm{pp}$. 729733). https://doi.org/10.1145/3236024.326483

88. Milligan, S. K. (2018). Methodological foundations for the measurement of learning in learning analytics. Proceedings of the 8th International Conference on Learning Analytics and Knowledge, 466-470. https://doi.org/10.1145/3170358.3170391

89. Moher, D., Liberati, A., Tetzlaff, J., \& Altman, D. (2009). Moher D, Liberati A, Tetzlaff J, Altman DG, Group PPreferred reporting items for systematic reviews and meta-analyses: The PRISMA statement. PLoS Med 6: e1000097. Open Medicine : A Peer-Reviewed, Independent, Open-Access Journal, 3, e123-30. https://doi.org/10.1016/j.jclinepi.2009.06.005

90. Morley, J., Floridi, L., Kinsey, L., \& Elhalal, A. (2019). From What to How: An Initial Review of Publicly Available AI Ethics Tools, Methods and Research to Translate Principles into Practices. ArXiv:1905.06876 [Cs]. http://arxiv.org/abs/1905.06876

91. Mu, S., Cui, M., \& Huang, X. (2020). Multimodal Data Fusion in Learning Analytics: A Systematic Review. Sensors, 20(23), 6856. https://doi.org/10.3390/s20236856

92. Munoz, R., Villarroel, R., Barcelos, T. S., Souza, A., Merino, E., Guiñez, R., \& Silva, L. A. (2018). Development of a software that supports multimodal learning analytics: A case study on oral presentations. Journal of Universal Computer Science, 24(2), 149-170.

93. Nakano, Y. I., Nihonyanagi, S., Takase, Y., Hayashi, Y., \& Okada, S. (2015). Predicting Participation Styles using Co-occurrence Patterns of Nonverbal Behaviors in 
Collaborative Learning. Proceedings of the 2015 ACM on International Conference on Multimodal Interaction, 91-98. https://doi.org/10.1145/2818346.2820764

94. Noel, R., Riquelme, F., Mac Lean, R., Merino, E., Cechinel, C., Barcelos, T. S., ... \& Munoz, R. (2018). Exploring collaborative writing of user stories with multimodal learning analytics: A case study on a software engineering course. IEEE Access, 6, 6778367798. https://doi.org/10.1109/ACCESS.2018.287680

95. Noroozi, O., Alikhani, I., Järvelä, S., Kirschner, P. A., Juuso, I., \& Seppänen, T. (2019). Multimodal data to design visual learning analytics for understanding regulation of learning. Computers in Human Behavior, 100, 298-304. https://doi.org/10.1016/j.chb.2018.12.019

96. Ochoa, X., Chiluiza, K., Méndez, G., Luzardo, G., Guamán, B., \& Castells, J. (2013). Expertise estimation based on simple multimodal features. Proceedings of the 15th ACM on International Conference on Multimodal Interaction, 583-590. https://doi.org/10.1145/2522848.2533789

97. Ochoa, X., \& Dominguez, F. (2020). Controlled evaluation of a multimodal system to improve oral presentation skills in a real learning setting. British Journal of Educational Technology, 51(5), 1615-1630. https://doi.org/10.1111/bjet.12987

98. Ochoa, X., Domínguez, F., Guamán, B., Maya, R., Falcones, G., \& Castells, J. (2018). The RAP system: Automatic feedback of oral presentation skills using multimodal analysis and low-cost sensors. Proceedings of the 8th International Conference on Learning Analytics and Knowledge, 360-364. https://doi.org/10.1145/3170358.3170406

99. Olsen, J. K., Sharma, K., Rummel, N., \& Aleven, V. (2020). Temporal analysis of multimodal data to predict collaborative learning outcomes. British Journal of Educational Technology, 51(5), 1527-1547. https://doi.org/10.1111/bjet.12982

100. Oviatt, S. (2013). Problem solving, domain expertise and learning: Ground-truth performance results for math data corpus. Proceedings of the 15th ACM on International Conference on Multimodal Interaction, 569-574. https://doi.org/10.1145/2522848.2533791

101. Oviatt, S., \& Cohen, A. (2013). Written and multimodal representations as predictors of expertise and problem-solving success in mathematics. Proceedings of the 15th ACM on International Conference on Multimodal Interaction, 599-606. https://doi.org/10.1145/2522848.2533793

102. Oviatt, S., Hang, K., Zhou, J., \& Chen, F. (2015). Spoken Interruptions Signal Productive Problem Solving and Domain Expertise in Mathematics. Proceedings of the 2015 ACM on International Conference on Multimodal Interaction, 311-318. https://doi.org/10.1145/2818346.2820743

103. Papamitsiou, Z., Pappas, I., Sharma, K., \& Giannakos, M. (2020). Utilizing Multimodal Data Through fsQCA to Explain Engagement in Adaptive Learning. IEEE Transactions on Learning Technologies, PP. https://doi.org/10.1109/TLT.2020.3020499

104. Papavlasopoulou, S., Sharma, K., \& Giannakos, M. N. (2018). How do you feel about learning to code? Investigating the effect of children's attitudes towards coding using eyetracking. International Journal of Child-Computer Interaction, 17, 50-60. https://doi.org/10.1016/j.ijcci.2018.01.004

105. Pardo, A., \& Siemens, G. (2014). Ethical and privacy principles for learning analytics: Ethical and privacy principles. British Journal of Educational Technology, 45(3), 438450. https://doi.org/10.1111/bjet.12152

106. Pijeira-Díaz, H. J., Drachsler, H., Kirschner, P. A., \& Järvelä, S. (2018). Profiling sympathetic arousal in a physics course: How active are students? Journal of Computer Assisted Learning, 34(4), 397-408. https://doi.org/10.1111/jcal.12271 
107. Praharaj, S., Scheffel, M., Drachsler, H., \& Specht, M. (2018). Multimodal Analytics for Real-Time Feedback in Co-located Collaboration. In V. Pammer-Schindler, M. PérezSanagustín, H. Drachsler, R. Elferink, \& M. Scheffel (Eds.), Lifelong TechnologyEnhanced Learning (pp. 187-201). Springer International Publishing. https://doi.org/10.1007/978-3-319-98572-5_15

108. Prestigiacomo, R., Hadgraft, R., Hunter, J., Locker, L., Knight, S., van den Hoven, E., \& Martinez-Maldonado, R. (2020). Learning-centred translucence: An approach to understand how teachers talk about classroom data. Proceedings of the Tenth International Conference on Learning Analytics \& Knowledge, 100-105. https://doi.org/10.1145/3375462.3375475

109. Prieto, L. P., Sharma, K., Dillenbourg, P., \& Jesús, M. (2016). Teaching analytics: towards automatic extraction of orchestration graphs using wearable sensors. In Proceedings of the sixth international conference on learning analytics \& knowledge (pp. 148-157).

110. Prieto, L. P., Sharma, K., Kidzinski, L., Rodriguez-Triana, M. J., \& Dillenbourg, P. (2018). Multimodal teaching analytics: Automated extraction of orchestration graphs from wearable sensor data. Journal of Computer Assisted Learning, 34(2), 193-203. https://doi.org/10.1111/jcal.12232

111. Prinsloo, P., \& Slade, S. (2013). An evaluation of policy frameworks for addressing ethical considerations in learning analytics. Proceedings of the Third International Conference on Learning Analytics and Knowledge - LAK '13, 240. https://doi.org/10.1145/2460296.2460344

112. Reilly, J. M., \& Schneider, B. (2019). Predicting the Quality of Collaborative Problem Solving through Linguistic Analysis of Discourse. In International Educational Data Mining Society. International Educational Data Mining Society. https://eric.ed.gov/?id=ED599226

113. Riquelme, F., Munoz, R., Mac Lean, R., Villarroel, R., Barcelos, T. S., \& de Albuquerque, V. H. C. (2019). Using multimodal learning analytics to study collaboration on discussion groups. Universal Access in the Information Society, 18(3), 633-643. https://doi.org/10.1007/s10209-019-00683-w

114. Riquelme, F., Noel, R., Cornide-Reyes, H., Geldes, G., Cechinel, C., Miranda, D., Villarroel, R., \& Munoz, R. (2020). Where are You? Exploring Micro-Location in Indoor Learning Environments. IEEE Access, 8, 125776-125785. https://doi.org/10.1109/ACCESS.2020.3008327

115. Rodriguez Triana, M. J., Prieto, L. P., Holzer, A. C., \& Gillet, D. (2017). The Multimodal Study of Blended Learning Using Mixed Sources: Dataset and Challenges of the SpeakUp Case (CONF). Joint Proceedings of the Sixth Multimodal Learning Analytics (MMLA) Workshop and the Second Cross-LAK Workshop Co-Located with 7th International Learning Analytics and Knowledge Conference; CEUR. https://infoscience.epfl.ch/record/229373

116. Romano, G., Schneider, J., \& Drachsler, H. (2019). Dancing Salsa with Machines-Filling the Gap of Dancing Learning Solutions. Sensors, 19, 3661. https://doi.org/10.3390/s19173661

117. Roque, F., Cechinel, C., Weber, T. O., Lemos, R., Villarroel, R., Miranda, D., \& Munoz, R. (2019). Using Depth Cameras to Detect Patterns in Oral Presentations: A Case Study Comparing Two Generations of Computer Engineering Students. Sensors, 19(16), 3493. https://doi.org/10.3390/s19163493 
118. Saquib, N., Bose, A., George, D., \& Kamvar, S. (2018). Sensei: Sensing Educational Interaction. Proceedings of the ACM on Interactive, Mobile, Wearable and Ubiquitous Technologies, 1(4), 161:1-161:27. https://doi.org/10.1145/3161172

119. Scheffel, M., Drachsler, H., Stoyanov, S., \& Specht, M. (2014). Quality Indicators for Learning Analytics. Educational Technology and Society, 17, 117-132.

120. Schneider, B. (2019). Unpacking Collaborative Learning Processes During Hands-on Activities Using Mobile Eye-Trackers. In Lund, K., Niccolai, G. P., Lavoué, E., HmeloSilver, C., Gweon, G., \& Baker, M. (Eds.), A Wide Lens: Combining Embodied, Enactive, Extended, and Embedded Learning in Collaborative Settings, 13th International Conference on Computer Supported Collaborative Learning (CSCL) 2019, Volume 1 (pp. 41-48). Lyon, France: International Society of the Learning Sciences.

121. Schneider, B., \& Blikstein, P. (2015). Unraveling Students' Interaction around a Tangible Interface Using Multimodal Learning Analytics. Journal of Educational Data Mining, 7(3), 89-116.

122. Schwendimann, B. A., Rodriguez-Triana, M. J., Vozniuk, A., Prieto, L. P., Boroujeni, M. S., Holzer, A., Gillet, D., \& Dillenbourg, P. (2017). Perceiving Learning at a Glance: A Systematic Literature Review of Learning Dashboard Research. IEEE Transactions on Learning Technologies, 10(1), 30-41. https://doi.org/10.1109/TLT.2016.2599522

123. Selwyn, N. (2020). Re-imagining 'Learning Analytics' ... a case for starting again? The Internet and Higher Education, 46, 100745. https://doi.org/10.1016/j.iheduc.2020.100745

124. Sharma, K., \& Giannakos, M. (2020). Multimodal data capabilities for learning: What can multimodal data tell us about learning? British Journal of Educational Technology, 51(5), 1450-1484. https://doi.org/10.1111/bjet.12993

125. Sharma, K., Leftheriotis, I., \& Giannakos, M. (2020). Utilizing Interactive Surfaces to Enhance Learning, Collaboration and Engagement: Insights from Learners' Gaze and Speech. Sensors, 20(7), 1964. https://doi.org/10.3390/s20071964

126. Sharma, K., Niforatos, E., Giannakos, M., \& Kostakos, V. (2020). Assessing Cognitive Performance Using Physiological and Facial Features: Generalizing across Contexts. Proceedings of the ACM on Interactive, Mobile, Wearable and Ubiquitous Technologies, 4(3), 95:1-95:41. https://doi.org/10.1145/3411811

127. Sharma, K., Papamitsiou, Z., \& Giannakos, M. (2019). Modelling Learners' Behaviour: A Novel Approach Using GARCH with Multimodal Data (pp. 450-465). https://doi.org/10.1007/978-3-030-29736-7_34

128. Sharma, K., Papamitsiou, Z., Olsen, J. K., \& Giannakos, M. (2020). Predicting learners' effortful behaviour in adaptive assessment using multimodal data. Proceedings of the Tenth International Conference on Learning Analytics \& Knowledge, 480-489. https://doi.org/10.1145/3375462.3375498

129. Shibani, A., Knight, S., \& Shum, S. B. (2019). Contextualizable Learning Analytics Design: A Generic Model and Writing Analytics Evaluations. Proceedings of the 9th International Conference on Learning Analytics \& Knowledge, 210-219. https://doi.org/10.1145/3303772.3303785

130. Shum, S. B., Sándor, Á., Goldsmith, R., Wang, X., Bass, R., \& McWilliams, M. (2016). Reflecting on reflective writing analytics: Assessment challenges and iterative evaluation of a prototype tool. Proceedings of the Sixth International Conference on Learning Analytics \& Knowledge - LAK '16, 213-222. https://doi.org/10.1145/2883851.2883955

131. Slade, S., \& Prinsloo, P. (2013). Learning Analytics Ethical Issues and Dilemmas. American Behavioral Scientist, 57, 1510-1529. https://doi.org/10.1177/0002764213479366 
132. Spikol, D., Ruffaldi, E., \& Cukurova, M. (2017). Using Multimodal Learning Analytics to Identify Aspects of Collaboration in Project-Based Learning.

https://doi.org/10.22318/cscl2017.37

133. Spikol, D., Ruffaldi, E., Dabisias, G., \& Cukurova, M. (2018). Supervised machine learning in multimodal learning analytics for estimating success in project-based learning. Journal of Computer Assisted Learning, 34(4), 366-377. https://doi.org/10.1111/jcal.12263

134. Spikol, D., Ruffaldi, E., Landolfi, L., \& Cukurova, M. (2017). Estimation of Success in Collaborative Learning Based on Multimodal Learning Analytics Features. 2017 IEEE 17th International Conference on Advanced Learning Technologies (ICALT), 269-273. https://doi.org/10.1109/ICALT.2017.122

135. Su, Y. N., Hsu, C. C., Chen, H. C., Huang, K. K., \& Huang, Y. M. (2013). A learning concentration detection system by using an artificial bee colony algorithm. In Applied Mechanics and Materials, 284, 1991-1995. Trans Tech Publications Ltd.

136. Tamura, K., Lu, M., Konomi, S., Hatano, K., Inaba, M., Oi, M., Okamoto, T., Okubo, F., Shimada, A., Wang, J., Yamada, M., \& Yamada, Y. (2019). Integrating Multimodal Learning Analytics and Inclusive Learning Support Systems for People of All Ages. In P.L. P. Rau (Ed.), Cross-Cultural Design. Culture and Society (pp. 469-481). Springer International Publishing. https://doi.org/10.1007/978-3-030-22580-3_35

137. Tan, S., Wiebrands, M., O'Halloran, K., \& Wignell, P. (2020). Analysing student engagement with 360-degree videos through multimodal data analytics and user annotations. Technology, Pedagogy and Education. Scopus. https://doi.org/10.1080/1475939X.2020.1835708

138. Vail, A. K., Grafsgaard, J. F., Wiggins, J. B., Lester, J. C., \& Boyer, K. E. (2014, November). Predicting learning and engagement in tutorial dialogue: A personality-based model. In Proceedings of the 16th international conference on multimodal interaction. 255-262. https://doi.org/10.1145/2663204.2663276

139. Verbert, K., Ochoa, X., De Croon, R., Dourado, R. A., \& De Laet, T. (2020). Learning analytics dashboards: The past, the present and the future. Proceedings of the Tenth International Conference on Learning Analytics \& Knowledge, 35-40. https://doi.org/10.1145/3375462.3375504

140. Vrzakova, H., Amon, M. J., Stewart, A., Duran, N. D., \& D'Mello, S. K. (2020). Focused or stuck together: Multimodal patterns reveal triads' performance in collaborative problem solving. Proceedings of the Tenth International Conference on Learning Analytics \& Knowledge, 295-304. https://doi.org/10.1145/3375462.3375467

141. Vujovic, M., Hernández-Leo, D., Tassani, S., \& Spikol, D. (2020). Round or rectangular tables for collaborative problem solving? A multimodal learning analytics study. British Journal of Educational Technology, 51(5), 1597-1614. https://doi.org/10.1111/bjet.12988

142. Warren, S. D., \& Brandeis, L. D. (1890). Right to privacy. Harvard Law Review, 4, 193.

143. Worsley, M. (2018). (Dis)engagement matters: Identifying efficacious learning practices with multimodal learning analytics. Proceedings of the 8th International Conference on Learning Analytics and Knowledge, 365-369. https://doi.org/10.1145/3170358.3170420

144. Worsley, M., \& Blikstein, P. (2018). A Multimodal Analysis of Making. International Journal of Artificial Intelligence in Education, 28(3), 385-419. https://doi.org/10.1007/s40593-017-0160-1

145. Worsley, M., \& Blikstein, P. (2015). Leveraging multimodal learning analytics to differentiate student learning strategies. Proceedings of the Fifth International Conference on Learning Analytics And Knowledge, 360-367. https://doi.org/10.1145/2723576.2723624 
146. Worsley, M., Scherer, S., Morency, L.-P., \& Blikstein, P. (2015). Exploring Behavior Representation for Learning Analytics. Proceedings of the 2015 ACM on International Conference on Multimodal Interaction, 251-258. https://doi.org/10.1145/2818346.2820737

147. Yueh, H.-P., Lin, W., Liu, Y., Shoji, T., \& Minoh, M. (2014). The Development of an Interaction Support System for International Distance Education. Learning Technologies, IEEE Transactions On, 7, 191-196. https://doi.org/10.1109/TLT.2014.2308952

148. Zook, M., Barocas, S., boyd, danah, Crawford, K., Keller, E., Gangadharan, S. P., Goodman, A., Hollander, R., Koenig, B. A., Metcalf, J., Narayanan, A., Nelson, A., \& Pasquale, F. (2017). Ten simple rules for responsible big data research. PLOS Computational Biology, 13(3), e1005399. https://doi.org/10.1371/journal.pcbi.1005399 